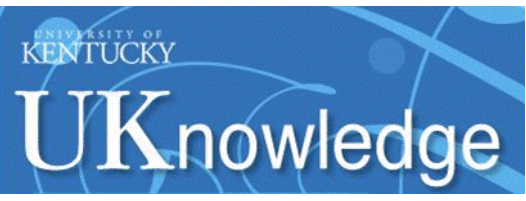

University of Kentucky

UKnowledge

9-26-2017

\title{
Structural Basis for EarP-Mediated Arginine Glycosylation of Translation Elongation Factor EF-P
}

\author{
Ralph Krafczyk \\ Ludwig-Maximilians-Universität München, Germany \\ Jakub Macošek \\ EMBL Heidelberg, Germany \\ Pravin Kumar Ankush Jagtap \\ EMBL Heidelberg, Germany \\ Daniel Gast \\ Ludwig-Maximilians-Universität München, Germany
}

See next page for additional authors

Right click to open a feedback form in a new tab to let us know how this document benefits you. Follow this and additional works at: https://uknowledge.uky.edu/ps_facpub

Part of the Enzymes and Coenzymes Commons, Microbiology Commons, Molecular Biology Commons, Pharmacy and Pharmaceutical Sciences Commons, and the Structural Biology Commons 


\section{Structural Basis for EarP-Mediated Arginine Glycosylation of Translation Elongation Factor EF-P}

Digital Object Identifier (DOI)

https://doi.org/10.1128/mBio.01412-17

Notes/Citation Information

Published in $m B i o$, v. 8, issue 5, e01412-17, p. 1-20.

Copyright @ 2017 Krafczyk et al.

This is an open-access article distributed under the terms of the Creative Commons Attribution 4.0 International license.

\section{Authors}

Ralph Krafczyk, Jakub Macošek, Pravin Kumar Ankush Jagtap, Daniel Gast, Swetlana Wunder, Prithiba Mitra, Amit Kumar Jha, Jürgen Rohr, Anja Hoffmann-Röder, Kirsten Jung, Janosch Hennig, and Jürgen Lassak 
ABSTRACT Glycosylation is a universal strategy to posttranslationally modify proteins. The recently discovered arginine rhamnosylation activates the polyprolinespecific bacterial translation elongation factor EF-P. EF-P is rhamnosylated on arginine 32 by the glycosyltransferase EarP. However, the enzymatic mechanism remains elusive. In the present study, we solved the crystal structure of EarP from Pseudomonas putida. The enzyme is composed of two opposing domains with Rossmann folds, thus constituting a B pattern-type glycosyltransferase (GT-B). While dTDP- $\beta$-L-rhamnose is located within a highly conserved pocket of the C-domain, EarP recognizes the KOW-like $\mathrm{N}$-domain of EF-P. Based on our data, we propose a structural model for arginine glycosylation by EarP. As EarP is essential for pathogenicity in $P$. aeruginosa, our study provides the basis for targeted inhibitor design.

IMPORTANCE The structural and biochemical characterization of the EF-P-specific rhamnosyltransferase EarP not only provides the first molecular insights into arginine glycosylation but also lays the basis for targeted-inhibitor design against Pseudomonas aeruginosa infection.

KEYWORDS Pseudomonas aeruginosa, Pseudomonas putida, TDP-rhamnose, glycosylation, glycosyltransferase, nucleotide sugar, posttranslational modification, ribosomes, translation

raci ranslation elongation is a nonuniform process and directly depends on the amino acids (aa) to be incorporated into the growing polypeptide chain (1). Due to its chemical and physical properties, proline delays the peptidyl transfer reaction (2), and ribosomes can even stall upon translation of distinct diprolyl-containing sequence motifs (Fig. 1) (3,4). Such ribosome stalling is alleviated by the eukaryotic and archaeal elongation factor $5 \mathrm{~A}(\mathrm{e} / \mathrm{aEF}-5 \mathrm{~A})(5-7)$ and its prokaryotic orthologue the bacterial translation elongation factor $P$ (EF-P) (8-14). The L-shaped EF-P is composed of three $\beta$-barrel domains and structurally resembles tRNA in both size and shape (15). EF-P binds to the polyproline-stalled ribosomes between the binding sites of peptidyl-tRNA (P-site) and the exiting tRNA (E-site) (16) and stimulates peptide bond formation by stabilization of the CCA end of the P-site prolyl-tRNA (Fig. 1) (17, 18). A conserved positively charged residue-located at the tip of the EF-P KOW-like N-domain-is essential for function $(11,17)$. However, for full EF-P activity, this residue is posttranslationally elongated (19). Certain bacteria-including Escherichia coli and Salmonella enterica-ß-lysinylate a conserved lysine, K34 EF-P, by EpmA. This EF-P-specific ligase
Received 8 August 2017 Accepted 23 August 2017 Published 26 September 2017 Citation Krafczyk R, Macošek J, Jagtap PKA, Gast D, Wunder S, Mitra P, Jha AK, Rohr J, Hoffmann-Röder A, Jung K, Hennig J, Lassak J. 2017. Structural basis for EarP-mediated arginine glycosylation of translation elongation factor EF-P. mBio 8:e01412-17. https://doi.org/ 10.1128/mBio.01412-17

Editor Richard Gerald Brennan, Duke University School of Medicine

Copyright $\odot 2017$ Krafczyk et al. This is an open-access article distributed under the terms of the Creative Commons Attribution 4.0 International license.

Address correspondence to Janosch Hennig, janosch.hennig@embl.de, or Jürgen Lassak, juergen.lassak@lmu.de.

R.K., J.M., J.H., and J.L. contributed equally to this work. 


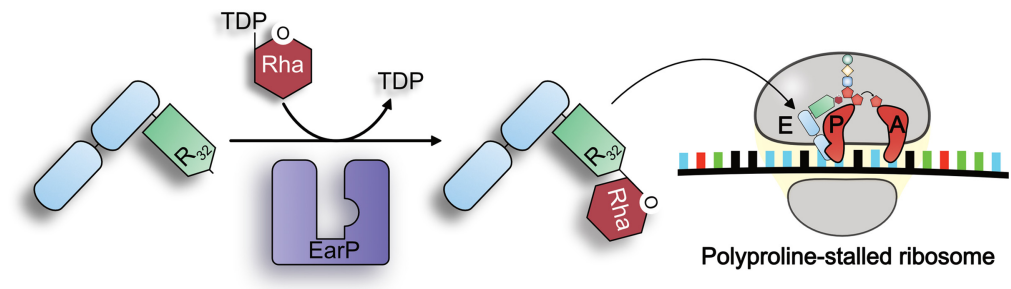

FIG 1 Activation and molecular function of EarP-arginine-type translation elongation factor EF-P. (Left) The bacterial translation elongation factor EF-P is composed of two OB-Fold domains (light blue) and one KOW-like N-domain (light green). In about $10 \%$ of all bacteria, EF-P is posttranslationally activated by $\alpha$-glycosylation of a strictly conserved arginine (R32) $(17,26)$. The glycosylation reaction is catalyzed by the EF-P-arginine rhamnosyltransferase EarP (purple) using dTDP- $\beta$-L-rhamnose (TDP-Rha [red]) as a substrate. (Right) Activated EF-P is recruited to polyproline-stalled ribosomes and binds between the $E$ and $\mathrm{P}$ sites. Thereby, R32 $2^{\mathrm{EF}-\mathrm{P}}$ and the attached rhamnose moiety presumably stabilize the CCA end of the P-site prolyl-tRNA, which in turn stimulates Pro-Pro peptide bond formation and thus alleviates the translational arrest.

uses $\beta$-(R)-lysine as the substrate, which is generated by isomerization of $\alpha$-(S)-lysine by employing the activity of the amino mutase EpmB (20-23). In contrast, activation of a phylogenetically distinct group of EF-Ps encoded in species such as Pseudomonas aeruginosa and Neisseria meningitidis depends on rhamnosylation of an arginine, R32 $2^{\mathrm{EF}-\mathrm{P}}$, in the equivalent position $(17,24,25)$. Rhamnosylation is mediated by the recently discovered inverting glycosyltransferase EarP, which utilizes dTDP-beta-Lrhamnose (TDP-Rha) as donor substrate, resulting in $\alpha$-rhamnosyl-arginine on the acceptor EF-P $(26,27)$. Unlike with the common and relatively well understood glycosylation of asparagine, sugar modifications on the guanidino group of arginine appear to be rare, and almost nothing is known about the molecular mechanism $(28,29)$. To date, there are only two reported cases of arginine glycosylation other than EF-P rhamnosylation. The first one described self- $\beta$-glycosylation of sweet corn amylogenin (30). In the second case, an effector glycosyltransferase termed NleB of enteropathogenic $E$. coli (EPEC) was shown to inactivate human cell death domain-containing proteins by $\mathrm{N}$-acetylglucosaminylation of arginine, with this being a major pathogenicity determinant during infection (31). Similarly, a lack of earP abolishes the pathogenicity of $P$. aeruginosa (17). Accordingly, solving the molecular mechanism of arginine rhamnosylation might pave the way to ultimately design and develop targeted inhibitors against EarP.

Here we present the X-ray crystal structure of EarP from Pseudomonas putida KT2440

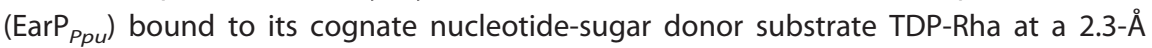
resolution (PDB accession number 5NV8). Together with reporting the results of nuclear magnetic resonance (NMR) spectroscopy analyses and an in vitro/in vivo biochemical enzyme characterization, we lay the foundation for understanding arginine glycosylation.

\section{RESULTS}

Despite low sequence conservation most nucleotide sugar dependent (Leloir-type) glycosyltransferases adopt one of two major folding patterns, GT-A or GT-B (28). However, so far, there is no available information on the structure and folding properties of EarP. We used SWISS-MODEL (32), Phyre ${ }^{2}$ (33), and the I-TASSER server for protein structure and function predictions (34-36) to generate fold recognition models of EarP from Pseudomonas putida (see Fig. S3A in the supplemental material). These predictions suggested the UDP- $N$-acetylglucosamine (UDP-GlcNAc)-dependent glycosyltransferases MurG from E. coli (MurG $\mathrm{ECO}_{\mathrm{C} O}$ ) (37) and O-GlcNAc transferase (OGT) from Xanthomonas campestris $\left(\mathrm{OGT}_{X c a}\right)(38)$ as structural orthologues. Accordingly, EarP $\mathrm{P}_{P \mathrm{pu}}$ adopts a clamp-like structure with two opposing Rossmann-like domains that are separated by an interdomain cleft (Fig. S3A). With this, the protein is presumably a GT-B-type glycosyltransferase (28). 
A

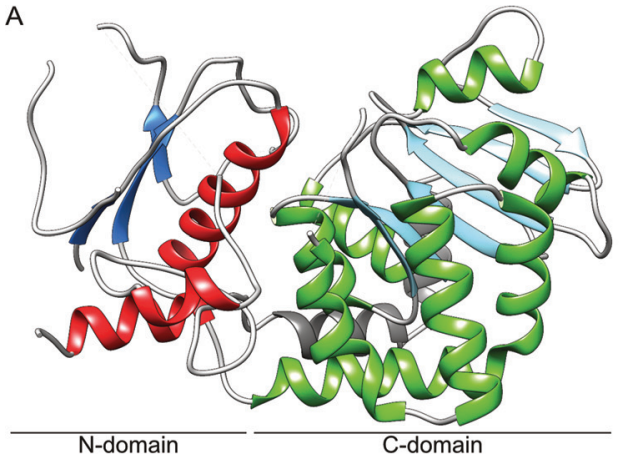

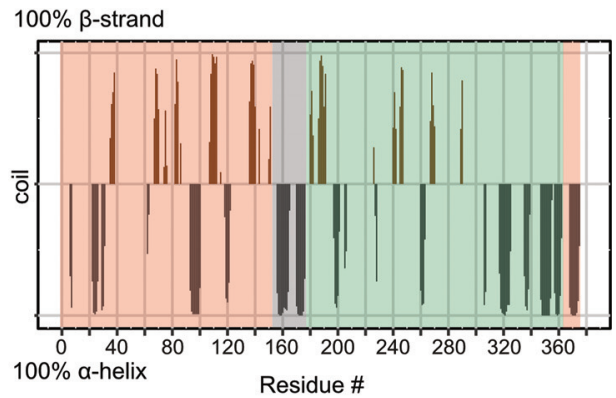

FIG 2 EarP folding pattern and topology. (A) Ribbon representation of the 2.3- $\AA$ crystal structure of EarP $P_{P p u}$. The illustration was generated with UCSF Chimera (82). Secondary-structure elements are shown, with $\alpha$-helices in red and green for the $\mathrm{N}$ - and $\mathrm{C}$-domains, respectively, and $\beta$-strands correspondingly in blue and cyan. The bipartite helix of the linker domain is grey. $\beta$-Strand $3, \alpha$-helix 5 , and short loops with weak electron density are also displayed here but are missing in the PDB coordinate file to improve statistics, as discontinuity in the electron density did not allow proper modeling. (B) Secondary structure of EarP determined by NMR secondary shifts. The secondary structure of individual amino acids is indicated as propensity to form either an $\alpha$-helix (grey) or a $\beta$-strand (brown). The amino acids with a propensity to adopt a random coil or lacking information about secondary structure were assigned zero values in the plot. The propensity values were obtained from $\mathrm{C}_{\alpha^{\prime}} \mathrm{C}_{\beta^{\prime}} \mathrm{NH}$, and $\mathrm{H}$ chemical shifts using TALOS+ (103). The N- and C-terminal EarP domains are boxed in peach and green, respectively. The interconnecting linker is boxed in grey.

Structure of Pseudomonas putida EarP. We were able to subsequently confirm the GT-B fold by having solved the crystal structure of $\operatorname{EarP}_{P p u}$ at 2.3- $\AA$ resolution (Fig. $2 \mathrm{~A}$; Data Set S2). Indeed, the EarP ${ }_{P p u}$ C-domain includes residues 184 to 361 and follows the Rossmann fold topology, with six $\beta$-strands ( $\beta 8$ to $\beta 13$ ) and seven $\alpha$-helices ( $\alpha 8$ to $\alpha 14$ ) (Fig. 2 and see Fig. 4A). On the other hand, the N-domain (aa 1 to 153 and 362 to 377) could only be built in part. Although weak electron density for likely other regions of the $\mathrm{N}$-domain was noticed, it was not sufficient to be unambiguously and reliably interpreted as particular missing parts of the protein chain. It is important to note that there is no indication that the diffraction data are twinned or anisotropic. The poor density of the $\mathrm{N}$-domain is not caused by misinterpretation of noncrystallographic symmetry as crystallographic symmetry, because choosing a space group with lower symmetry does not improve the electron density. Yet, the structure has a higher-thanusual R-free (35.1\%) value at this resolution, which cannot be explained by a simple absence of disordered regions. This is likely due to the $\mathrm{N}$-domain adopting different conformations in different unit cells, causing crystal disorder. The potential mobility of the $\mathrm{N}$-domain is further supported by higher average B-factors for this domain than for the C-domain (61 $\AA^{2}$ versus $46 \AA^{2}$ ) (see Fig. S3B for B-factors mapped onto the protein structure). In addition, our rigorous attempts to obtain crystals in different space groups by screening various crystallization conditions were not successful. In the predicted structure (Fig. S3A, model 2), the $\mathrm{N}$-domain features a central $\beta$-sheet of seven $\beta$-strands ( $\beta 1$ to $\beta 7$ ), surrounded by the $\alpha$-helices ( $\alpha 1$ to $\alpha 5$ and $\alpha 15$ ) (see Fig. 4A and Fig. S3A). In the crystal structure, only $\beta$-strands $\beta 1, \beta 2$, and $\beta 3$, as well as $\alpha$-helixes $\alpha 1$, $\alpha 5$, and $\alpha 15$, are modeled (Fig. 2A). However, the missing structural elements in the protein $\mathrm{N}$-domain are not in close vicinity to the active site according to the fold recognition model (Fig. S3A, model 2), and we did not observe any unassigned electron density in the vicinity of the ligand. Thus, despite this disorder, our crystal structure still provides crucial information important for understanding ligand binding and the catalytic mechanism. For structure validity assessment, the EarP crystal structure with electron density is shown in Fig. S4 in the supplemental material.

Furthermore, the presence of the predicted strands and helices and thus the validity of the model and crystal structure could be confirmed by NMR secondary chemical shifts (Fig. 2B). A prerequisite for this analysis is the backbone chemical shift assignment by triple-resonance NMR experiments. The relatively large size of EarP $\mathrm{P}_{P u}$ at $43 \mathrm{kDa}$ exceeds the sensitivity limitations of NMR, demanding deuteration in order to decrease 
cross-relaxation effects and to decrease the signal line width. Nonetheless, using transverse relaxation-optimized spectroscopy (TROSY)-based experiments, we were able to assign $62 \%$ of the $\operatorname{EarP}_{P p u}$ backbone.

The two domains are interconnected by a bipartite helix $(\alpha 6, \alpha 7)$ comprising aa 156 to 176 . This linker region together with an unstructured segment that positions $\alpha 15$ in the vicinity of the $\mathrm{N}$ terminus defines the floor of the cleft that separates the domains (Fig. 2A and see Fig. 4).

Based on these and previous data $(17,24-27)$, EarP was built in the carbohydrateactive enzymes (CAZy) database (39) and now represents the new glycosyltransferase family GT104.

Analysis of the TDP- $\beta$-L-rhamnose binding site in the EarP C-domain. In Leloirtype GT-B glycosyltransferases, the nucleotide-sugar binding site is canonically located in the protein C-domain (40). Similarly, TDP-Rha in the EarP $P_{P p u}$ crystal structure is located in a binding pocket that is composed of residues located in the C-domain (Fig. 3A). F191 EarP, F252 EarP, and F258 EarP side chains form an aromatic cage that stacks against the base of the nucleotide moiety of TDP-Rha. The sugar ring of the nucleotide is then specifically recognized by a hydrogen bond between the hydroxyl group on C3' of the sugar and the side chain of Q255 EarP. The diphosphate is recognized by hydrogen bonds formed with the side chain guanidine of R271EarP, the Y193EarP side chain hydroxyl, and backbone amides of E273 EarP and D274EarP. The binding pocket is closed by the bulky side chain of Y193EarP, which may sterically ensure proper positioning of the rhamnose sugar (Fig. 3A). The rhamnose sugar itself does not seem to make any contact with the protein and is solvent exposed. We further confirmed this by saturation transfer difference (STD) NMR experiments (41), where we did not observe any difference signal from the rhamnose moiety but did observe one from the TDP moiety of TDP-Rha (Fig. S5A).

In parallel, small-angle X-ray scattering (SAXS) of free $\operatorname{EarP}_{P p u}$ and $\operatorname{EarP}_{P p u}$ bound to TDP-Rha has been performed (Fig. S3D). The overall shape of the molecule could be validated to be the same in solution. Protein backbone conformational changes upon TDP-Rha binding are confirmed by chemical shift perturbations (see Fig. 7B); however, SAXS indicates that there are no large $(>10-\AA)$ conformational changes or movements of the two Rossmann fold domains with respect to each other upon binding of TDP-Rha, as the scattering density does not change from that in the free state. To show that TDP-Rha is bound to EarP under SAXS experimental conditions, STD NMR experiments were performed. They confirm again that TDP-Rha binding occurs with the ligand at a 7-fold excess compared to the amount of protein (Fig. S5B).

Database mining identified 432 EarP homologues representing about $10 \%$ of sequenced bacteria (Data Set S3) (17). Phylogenetically, EarP originated presumably in the betaproteobacterial subdivision and was horizontally transferred into the gammaproteobacterial orders of Pseudomonadales, Aeromonadales, and Alteromonadales (17). It can also be found in certain Fusobacteria, Planctomycetes, and Spirochetes (17).

In order to identify conserved amino acids, we used Clustal Omega (42) and generated a multiple-sequence alignment (Fig. 4A). We found 49 residues with a sequence conservation of $\geq 95 \%$. Mapping of these residues onto the crystal structure revealed an accumulation at or near the interdomain cleft (Fig. 4B), including the binding pocket for the nucleotide sugar donor substrate (Fig. 3A), which is highly supportive of the correctness of the solved structure.

To substantiate our structural findings with biochemical data, we prepared EarP $P_{P p u}$ constructs with single-amino-acid substitutions of the individual residues forming the binding pocket and tested the activities of the $\operatorname{EarP}_{P p u}$ variants both in vivo and in vitro (Fig. 5). This included F191 EarP, F252 EarP, and F258EarP, which form the aromatic pocket, as well as Y193 EarP, Q255 EarP, R271 EarP, and D274EarP, which are involved in hydrogen bond networking (Fig. 5B).

Previously, we could show that the heterologous expression of efp and earP from Shewanella oneidensis in E. coli can fully complement a lack of EF-P (17) with respect to 
A

B
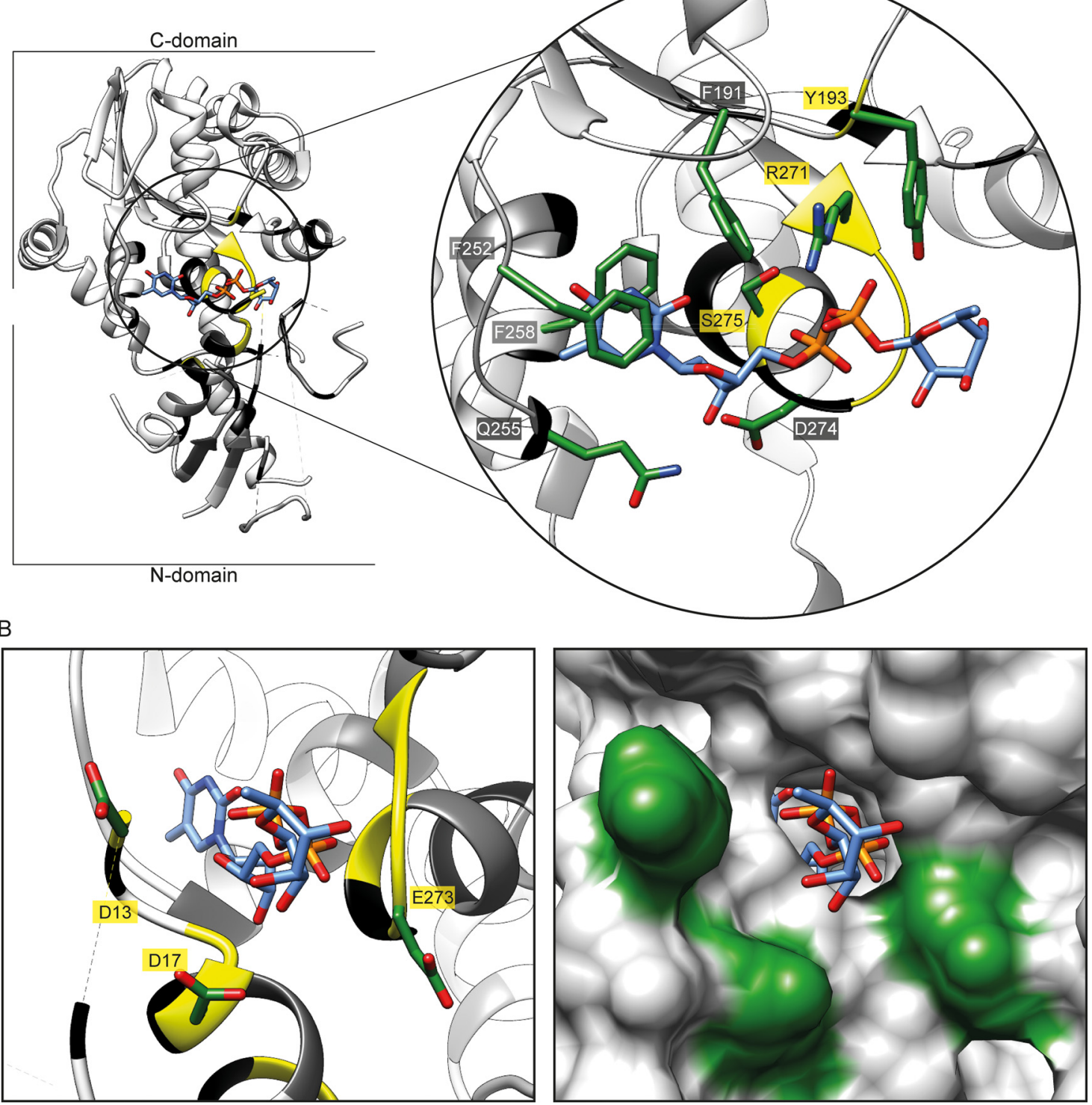

FIG 3 EarP TDP- $\beta$-L-rhamnose binding site. (A, left) Three-dimensional structure of EarP $P_{P u}$ in a ribbon representation. The TDP-Rha binding pocket in the C-domain is circled in black. (Right) Zoom into the nucleotide-sugar binding pocket with bound TDP-Rha (blue sticks). Important residues for TDP-Rha positioning are depicted as green sticks and labeled with single-letter code identifiers. (B, left) Ribbon representation of the nucleotide-sugar binding pocket with stick representation of bound TDP-Rha (blue sticks) as well as the three invariant residues D13, D17, and E273 (green sticks), which are presumably involved in catalysis. (Right) Surface representation of the nucleotide-sugar binding pocket with stick representation of bound TDP-Rha (blue). Surfaces of D13, D17, and E273 are in green. Ribbons are color coded according to their degree of conservation, as follows: yellow, $100 \%$; black, $\geq 95 \%$; dark grey, $\geq 90 \%$; light grey, $\geq 50 \%$; and white, $<50 \%$ identical residues in all analyzed EarP orthologues. The electron density for TDP-Rha bound to EarP is shown in Fig. S3C. All illustrations were generated with UCSF Chimera (82).

the activation of the lysine-dependent acid stress response by the transcriptional activator CadC (11). Similarly, coproduction of wild-type EF-P $P_{P p u}$ and wild-type EarP $P_{P p u}$ (WTEarP) can restore $\beta$-galactosidase activity in an E. coli $\mathrm{P}_{\text {cadBA }}$ ::lacZ $\triangle$ efp strain (Fig. 5A and $\mathrm{S1B}$ ). From the nine tested $\mathrm{EarP}_{P p u}$ substitution variants, we measured reduced $\beta$-galactosidase activities for the variants F191 AEarP, Y193A EarP, R271 A ${ }^{\text {EarP }}$, S275A EarP, and Y291A EarP. The variants R271 $A^{\text {EarP }}$ and Y291AEarP failed to induce $\beta$-galactosidase expression at all (Fig. 5B and S1B).

In parallel, the enzymatic activity of EarP $P_{P p u}$ was investigated in vitro by employing an anti-ArgRha antibody. The antibody was raised against a chemically synthesized glycopeptide antigen (SGR RhaNAAIVK) and specifically detects arginine rhamnosylation 
A

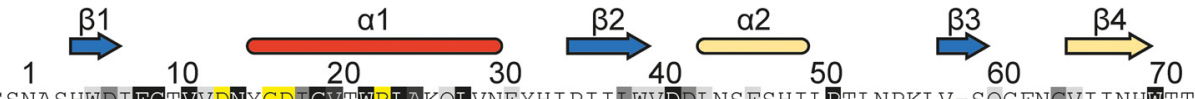

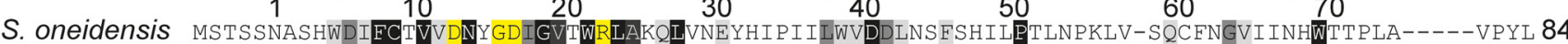

P. aerugionsa ------MASWDIFCSVVDNYGDIGVTWRLARQIAGEHGQAVRLWVDEPRAFVRICPQADPA-IQVQRHAGVEVRAWDKAWSP------VE 77

P. putida -----MKATWDIFCSVVDNYGDI GV TWRLARQLVAEHGLAVRLWV DDLNAET PMCPGADAT-AAQQWQHGVDVRHWDAAWLP------VA 78

N. meningitidis - MNTP-PFVCWIECKVIDNFGDIGVSWRLARVLHRELGWQVHLWTDDVSALRALCEDLP-DVPC--VHQDIHVRTWHSDA--ADID-TAP 82

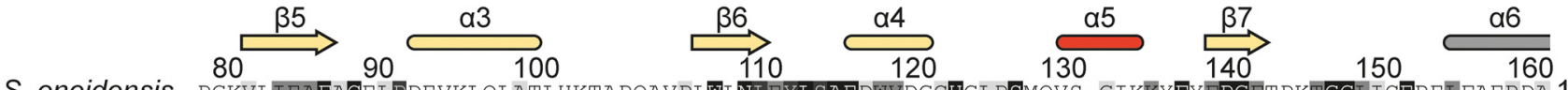

S. oneidensis PGKVLIEAEACELEDEVKLQLATLHKTAPQAVPLWL NLEYLSAEDWVDGCHGLPSMQVS-GIKKYFIYFPGETPKTGGLICERETFAERDA 173

$P$. aerugionsa AADVVIEAGACELEEAHRQAMRER----GRPSIWLNLEYLSAEEWIGGCHALPSLQP-CGLSKY EF FPG REPSGGLLRDAGLLERRRS 161

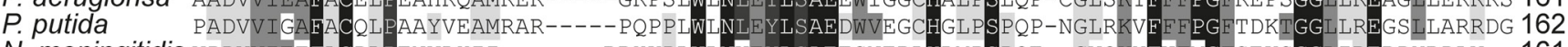

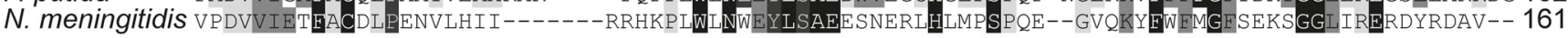

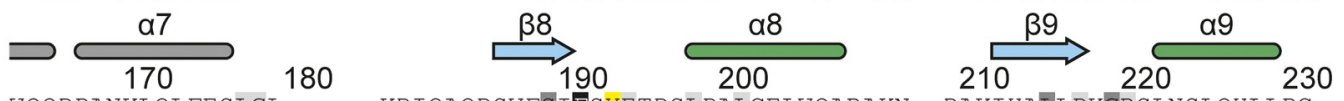

S. oneidensis WQQDPANKLQLFESLGL-----KDIQAQDSVFSIESYETDSLPALCELWQARAKN--DAKIHAIILPKGRSLNSLQHLLPC----PVDAL 251

$P$. aerugionsa FQASARAQEAFLAALGVRR------K-VGERLLSLEAYENPALRSWLDSLRRAR-----QPSLLLVPEGRVLADVAGWLQLPG-I----- 233

$P$ putida FQQSAEARRAFLQGLGVDL------V-PGALLISLEAYENPQLGNWLDALATAD-----QPCHLIVPQGRVVAGLSQWLGEGP-L----- 234

N. meningitidis ---RFDTEALRQ-----WLMLPEK--NAPEWILGGYRSDVWAKWLDMWQQA---GS---LTLILAGAQI I DSLKQSGVIPQD---ALQ 231

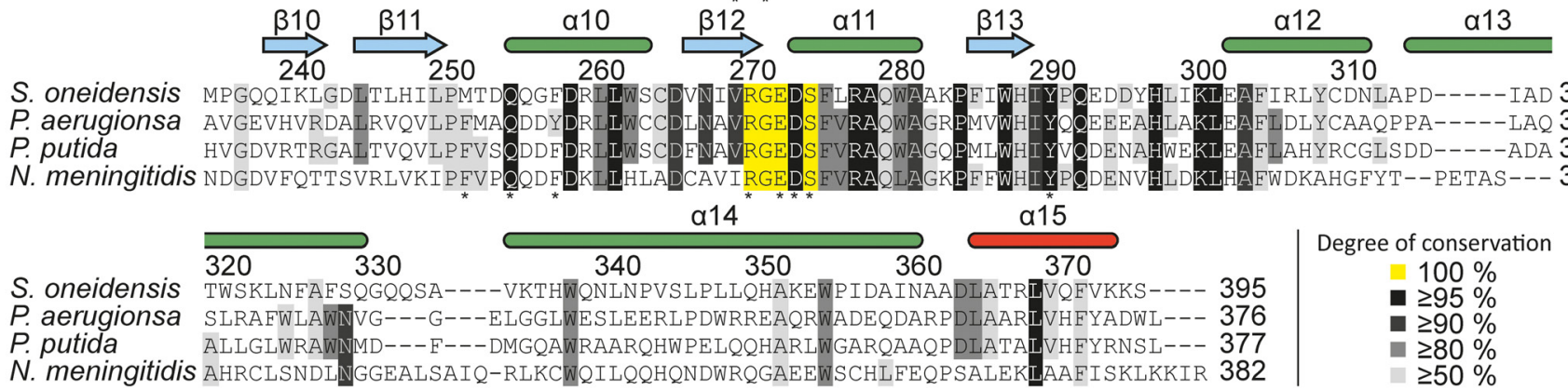

B

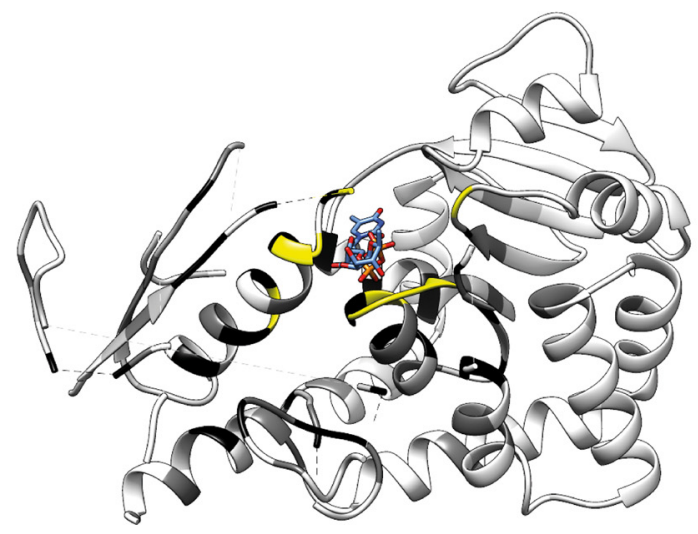

N-domain

C-domain

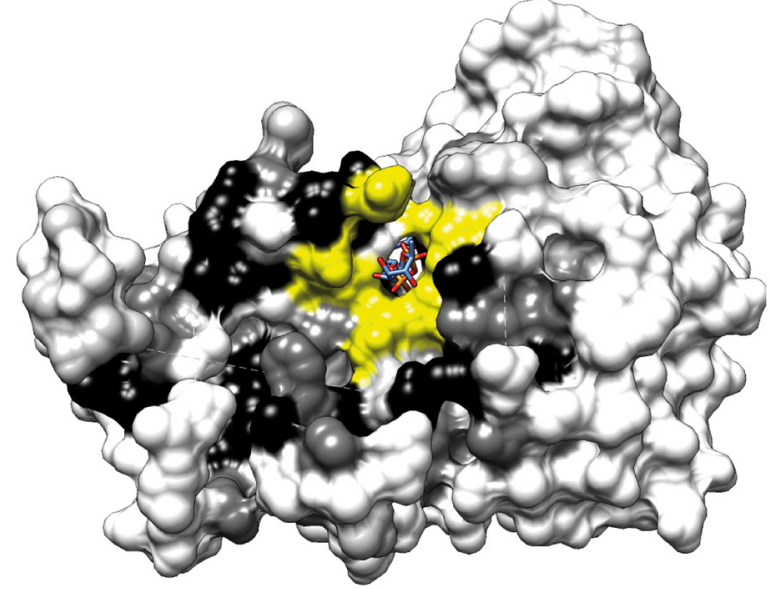

N-domain

C-domain

FIG 4 Evolutionary conservation of amino acids in EarP homologues. (A) Multiple-sequence alignment of EarP proteins from Shewanella oneidensis, P. aeruginosa, P. putida, and Neisseria meningitidis as a selection from the alignment of 432 protein sequences that were collected from the NCBI database (Data Set S3). The multiple-sequence alignment was generated using Clustal Omega (104). Secondary-structure elements of EarP are shown and based on the EarP ${ }_{P p u}$ crystal structure, NMR analysis, and predictions by MINNOU (105). $\alpha$-Helices are in red and green for the N-and C-domains, respectively, and $\beta$-strands are in blue and cyan. The bipartite helix of the linker domain is grey. Helices and $\beta$-strands not resolved in the crystal structure are yellow. Amino acids selected for mutational analysis are indicated by asterisks. (B) The EarP $P_{p p u}$ crystal structure was colored according to the degree of conservation of the respective amino acids. Ribbon (left) and surface (right) representations of the EarP $P_{p p u}$ crystal structure are shown. Colors indicate the following: yellow, 100\%; black, $\geq 95 \%$; dark grey, $\geq 90 \%$; light grey, $\geq 50 \%$; and white, $<50 \%$ identical residues in all analyzed EarP orthologues. Illustrations were generated with UCSF Chimera (82).

(see Materials and Methods) (Fig. S1A). This in turn enabled the quantification of rhamnosylation rates of EF-P $P_{P p}$ by Western blot analysis (Fig. 5C and D). In a first step, the $K_{m}$ and $k_{\text {cat }}$ of WTEarP were determined to be $53 \mu \mathrm{M}$ and $35 \mathrm{~min}^{-1}$, respectively (Fig. 5B, C, and D).

We wondered whether this $K_{m}$ makes sense physiologically and therefore analyzed the cellular TDP-Rha levels in P. putida, P. aeruginosa, and E. coli, which were $3.5 \mathrm{mM}$, 


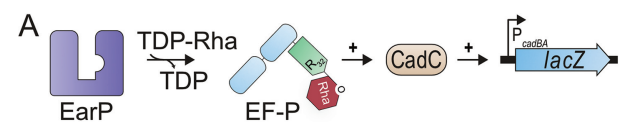

B

\begin{tabular}{|c|c|c|c|c|}
\hline & $\begin{array}{l}\text { Identity/ } \\
\text { Similarity }\end{array}$ & $\begin{array}{l}\text {-galactosidas } \\
\text { activity [MU] }\end{array}$ & $\begin{array}{l}\text { TDP-Rh } \\
\mathrm{K}_{\mathrm{m}}[\mu \mathrm{M}]\end{array}$ & $\mathrm{k}_{\mathrm{cat}}\left[\mathrm{min}^{-1}\right]$ \\
\hline $\begin{array}{l}\text { WT } \\
\text { F191A } \\
\text { Y193A } \\
\text { F252A } \\
\text { Q255A } \\
\text { F258A } \\
\text { R271A } \\
\text { D274A } \\
\text { S275A } \\
\text { Y291A }\end{array}$ & $\begin{array}{c}99 / 99 \\
100 / 100 \\
77 / 81 \\
98 / 98 \\
32 / 100 \\
100 / 100 \\
96 / 100 \\
100 / 100 \\
99 / 99\end{array}$ & $\begin{array}{c}3200 \\
1100 \\
900 \\
3100 \\
3500 \\
3800 \\
20 \\
3600 \\
2700 \\
20\end{array}$ & $\begin{array}{c}53 \\
810 \\
760 \\
3400 \\
210 \\
530 \\
250 \\
2200 \\
100 \\
170\end{array}$ & $\begin{array}{l}35 \\
0.01 \\
0.01 \\
2.3 \\
5.0 \\
0.14 \\
0.09 \\
0.12 \\
0.07 \\
0.07\end{array}$ \\
\hline
\end{tabular}

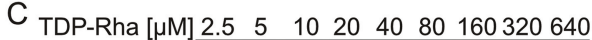

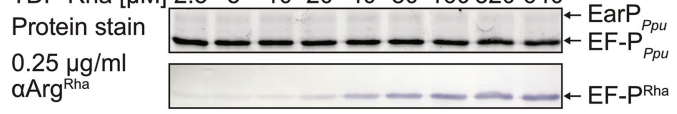

$\mathrm{D}$

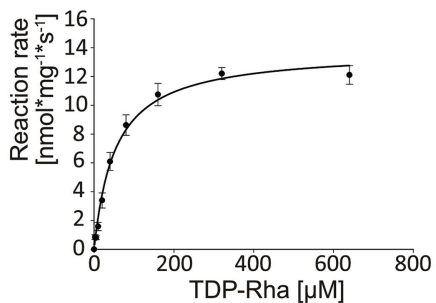

FIG 5 Analysis of kinetic parameters and in vivo activities of $\operatorname{EarP}_{P p u}$ variants. (A) Molecular principle of the in vivo EF-P $P_{P p u}$ functionality assay. This assay is based on the lysine decarboxylase acid stress response of $E$. coli, the CadABC module (68). At low pH and with the concomitant presence of lysine, the transcriptional activator CadC activates the promoter of its two downstream genes $\left(P_{\text {cadBA }}\right)$ and with this induces expression of lacZ in an E. coli MG1655 $P_{C a d B A}:: 1 a c Z$ strain (11). Proper translation of CadC is dependent on the presence of EF-P and its corresponding modification system, and thus $\beta$-galactosidase activity can be taken as a direct readout for EF-P and EarP functionality. (B) Degree of conservation (identity/similarity) in percent, in vivo activities, and kinetic parameters of tested single-amino-acid exchange variants of EarP $_{P p u}$. In vivo EarP $P_{P p}$ activities were determined by measuring the $\beta$-galactosidase activities of an E. coli MG1655 $P_{c a d B A}:$ IacZ $\Delta e f p$ strain heterologously expressing efp $p_{P p u}$ together with wild-type or mutant earP $P_{P p u}$ genes from o/n cultures in $\mathrm{LB}$ (pH 5.8). Background corrected mean values from three independent measurements are shown. Standard deviations were determined from three independent experiments to be $\leq 10 \%$; the $K_{m}$ and $k_{\text {cat }}$ of wild-type EarP $P_{P u}(\mathrm{WTEarP})$ and variants with single-amino-acid substitutions are given in micromolar concentrations and per minute, respectively. Standard errors were determined by SigmaPlot to be $<20 \%$. (C, top) 2,2,2-Trichlorethanol (TCE) protein stain (75) of a representative SDS gel used for determination of kinetic parameters. Fixed amounts of EF-P $\mathrm{Ppu}_{\text {pu }}(2.5 \mu \mathrm{M})$ and WTEarP $(0.1 \mu \mathrm{M})$ were incubated with various concentrations of TDP-Rha for $20 \mathrm{~s}$ and subjected to SDS-PAGE. (Bottom) Detection of rhamnosylated EF-P $P_{P p u}$. EF- $P_{P p u}$ was visualized after Western blotting using $0.25 \mu \mathrm{g} / \mathrm{ml}$ anti-ArgRha. (D) TDP-Rha saturation curve of WTEarP. Band intensities from panel C were quantified using ImageJ (76). Reaction rates were calculated as means of four independent measurements. Standard deviations are shown as error bars for each concentration.

$2.0 \mathrm{mM}$, and $4.0 \mathrm{mM}$, respectively (see Materials and Methods and Fig. S6). In good accordance with our measurements, the physiological TDP-Rha concentration in Lactococcus lactis was previously determined to be as high as $1 \mathrm{mM}$ (43). Thus, within a bacterial cell, the donor substrate reaches saturating concentrations, according to the WTEarP $K_{m}$ measurements.

Next, the $K_{m}$ and $k_{\text {cat }}$ of EarP $P_{P p}$ substitution variants were determined and compared to those of the wild-type protein. Strikingly, all earP mutations affected enzymatic activity (Fig. 5B and S2B). Depending on the substituted residue, the $K_{m}$ increased up to 60 -fold for the F252A EarP variant $\left(K_{m}=3.4 \mathrm{mM}\right)$. Conversely, the $k_{\text {cat }}$ decreased up to 3,500 times when we measured the kinetics of the F191 AarP and Y193A EarP variants.

To exclude the possibility that decreased enzyme activity was due to fold disruption, selected EarP $P_{P u}$ variants (F191A EarP, Y193AEarP, F252AEarP, R271AEarP, D274AEarP, and Y291A EarP) were analyzed by NMR ${ }^{1} \mathrm{H}-{ }^{15} \mathrm{~N}$ heteronuclear single quantum coherence (HSQC) experiments (Fig. S7). All tested substitution variants showed no structural alterations from the wild-type protein, except for the D274A EarP variant. The structural instability of this EarP variant might be a result of disrupting a salt bridge that is formed between the side chains of D274EarP in the protein C-domain and an equally conserved arginine at position 23 (R23EarP) in the protein N-domain (Fig. 4). This salt bridge might be of importance in clamping both EarP domains together, and a lack of it might therefore destabilize the protein. Indeed, further purification of the D274AEarP variant by size exclusion chromatography $(\mathrm{SEC})$ revealed an elution pattern with three distinct EarP peaks, indicating a certain degree of protein aggregation. However, the lowest molecular peak in the D274AEarP SEC profile is congruent with the one that we found when subjecting WTEarP to SEC. Accordingly, $K_{m}$ (TDP-Rha) and $k_{\text {cat }}$ values were determined from this protein fraction to be $206 \mu \mathrm{M}$ and $0.74 \mathrm{~min}^{-1}$, respectively (Fig. 5B).

In parallel, a bacterial two-hybrid analysis (44) was set up to investigate interactions between EF-P $P_{P p u}$ and WTEarP as well as the above-mentioned nine substitution variants 
A

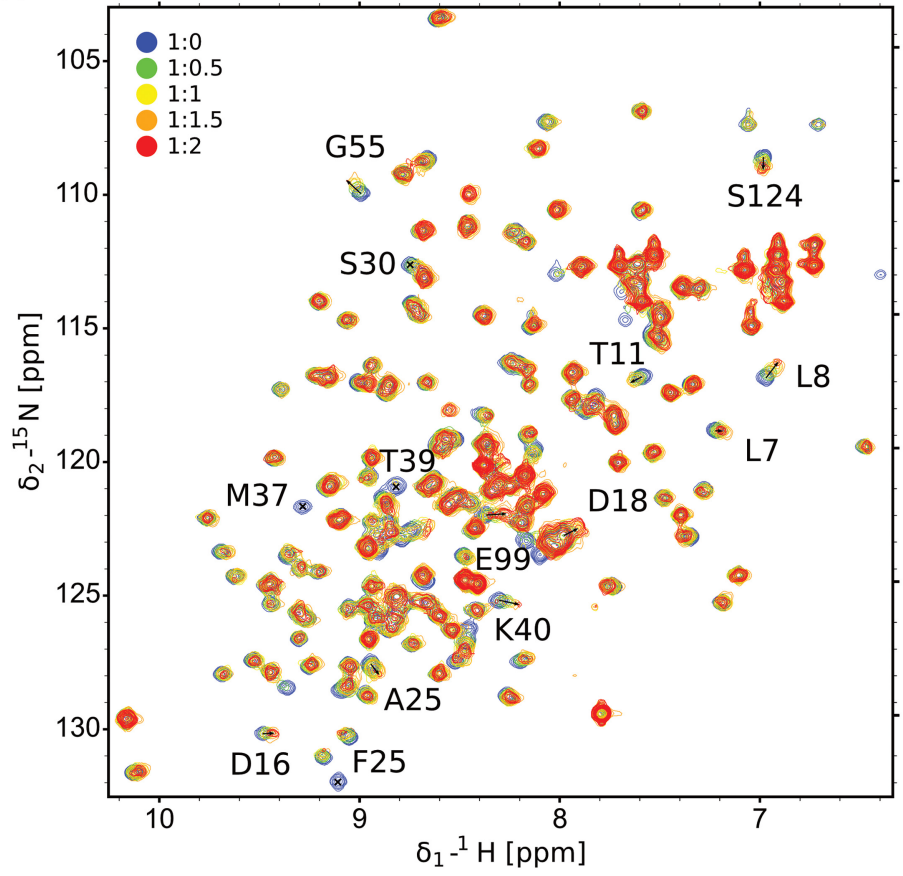

B

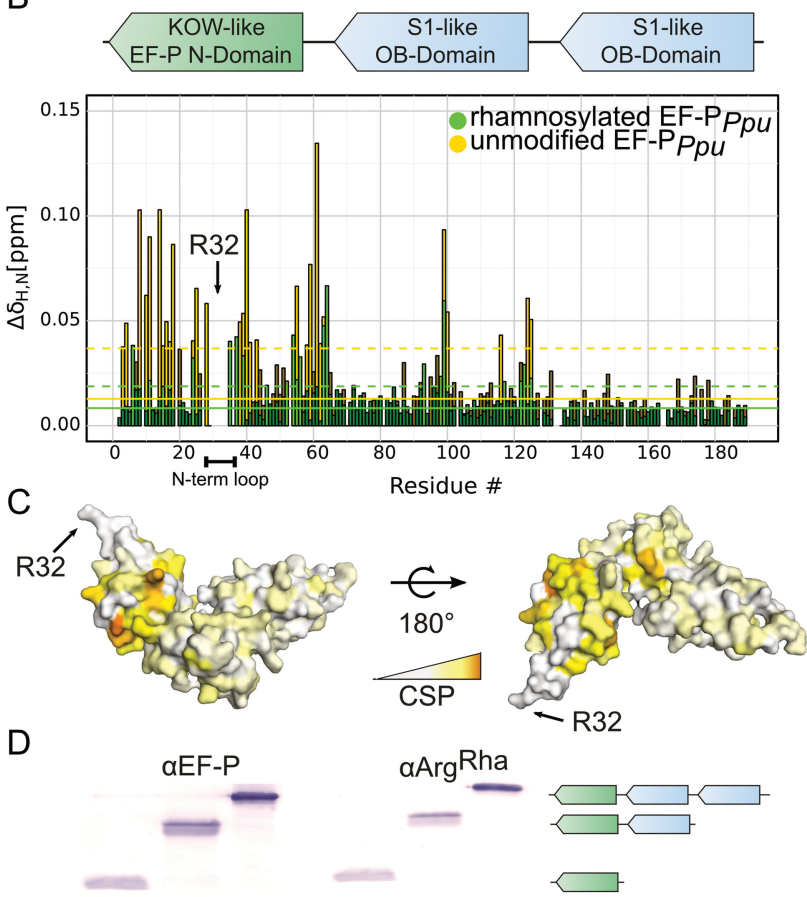

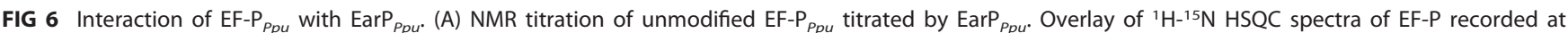
different titration steps. EF-P was titrated in a 1:2 EF-P $\mathrm{P}_{P p u} /$ EarP $_{P p u}$ molar ratio. Color coding for respective titration steps is indicated in the upper left corner. Examples of peaks with high chemical-shift perturbations (CSPs) or severe line broadening are shown by labels indicating the assignment of given peaks. (B, top) Domain structure of EF-P. EF-P consists of three $\beta$-barrel domains. The KOW-like EF-P N-domain harbors the rhamnosylation target R32EF-P. (Bottom) CSPs

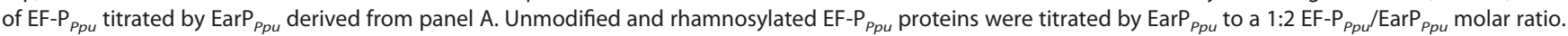
To analyze the interaction, CSPs were calculated as described in Materials and Methods and plotted against residue numbers. Color coding is indicated in the upper right corner. Full lines indicate median CSPs, dashed lines indicate median CSPs plus standard deviations, and residues with CSPs higher than the median plus standard deviation are shown in brighter shades of the colors. The N-terminal loop containing rhamnosylation target R32 $2^{\mathrm{EF}-\mathrm{P}}$ is indicated. (C) CSPs of unmodified EF-P $P_{P p u}$ titrated by EarP $P_{P p u}$ plotted on the model of EF-P from P. aeruginosa (45) (PDB accession number 3OYY) using a white-to-orange gradient, where white represents the weakest CSP and orange depicts the strongest CSP. The position of R32EF-P is indicated. (D) Rhamnosylation experiments using full-length EF-P $P_{P p u}$ and C-terminally truncated variants (EF-P $P_{P p u}$ with aa 1 to 128 , EF-P $P_{P p u}$ with aa 1 to 65 ). EF-P was detected using $0.2 \mu$ g/ml anti-EF-P. Rhamnosylation of purified protein was detected using $0.25 \mu \mathrm{g} / \mathrm{ml}$ anti-Arg Rha The domain structure of the respective protein variants is indicated as in panel $B$.

(Fig. 5B). Therefore, fusions were generated with two complementary fragments, T25 and T18, encoding segments of the catalytic domain of the Bordetella pertussis adenylate cyclase CyaA. If EF-P Ppu and WTEarP do interact, then CyaA is reconstituted, which in turn allows induction of the lac promoter and results in lacZ expression. Accordingly, $\beta$-galactosidase activity is a measure of the interaction strength. When coproducing EF-P $P_{P p u}$ with WTEarP, we determined ca. $250 \mathrm{MU}$, whereas combinations with solely T25 and T18 resulted in $<60 \mathrm{MU}$, thus defining the threshold of the assay (Fig. S1C). Except for the R271 A EarP and Y291 A EarP proteins, all other variants were below this threshold, indicating that alterations in the donor binding site might also affect acceptor binding (Fig. S1C).

The KOW-like EF-P N-domain is sufficient for EarP-mediated rhamnosylation. To test which part of EF-P is involved in the interaction with EarP, NMR chemical shift perturbation experiments were performed by comparing ${ }^{1} \mathrm{H}-{ }^{-15} \mathrm{~N} \mathrm{HSQC}$ results between unbound EF-P $P_{P p u}$ and EarP $P_{P p u}$-bound EF-P $P_{P p u}$ (Fig. 6A). Triple-resonance experiments of EF- $P_{P p u}$ enabled backbone assignment, with a sequence coverage of $97 \%$. Missing assignments are for residues S123, R133, N140, V164, D175, and G185. The assignment also enabled secondary-structure determination from secondary chemical shifts and confirmed the validity of the EF-P model for $P$. putida, based on the crystal structure of $P$. aeruginosa EF-P (Fig. S3E) (45). The titration experiment showed clear chemical shift perturbations in the N-terminal acceptor domain of EF-P $P_{P p u}($ Fig. 6B and C). However, R32 $2^{\mathrm{EF}-\mathrm{P}}$ and residues surrounding the rhamnosylation site (e.g., S30 ${ }^{\mathrm{EF}-\mathrm{P}}, \mathrm{G} 31^{\mathrm{EF}-\mathrm{P}}, \mathrm{R} 32^{\mathrm{EF}-\mathrm{P}}$, 
N33 ${ }^{\mathrm{EF}-\mathrm{P}}$ ) are severely line broadened beyond detection. Therefore, chemical shift perturbation values cannot be determined for these and vicinal residues. This line broadening is an indication that they are bound by $\operatorname{EarP}_{P p u}$ and thus have rotational correlation times expected for a complex of that size. Several residues located in the S1-like OB-domain are also slightly affected. However, this is not necessarily due to direct contacts with EarP $_{P p u}$ but might also be propagating effects. Therefore, we also investigated in vitro rhamnosylation of truncated EF- $P_{P p u}$ variants comprising either amino acids 1 to 128 or amino acids 1 to 65 (Fig. 6D). Both truncations were readily rhamnosylated by EarP $\mathrm{Ppu}_{\text {, }}$ further corroborating that EF-P contact sites are predominantly located in the KOW-like N-domain.

In addition, we compared NMR interactions between EarP $P_{P p u}$ and unmodified EF- $P_{P p u}$ or rhamnosylated EF-P $P_{P p u}$. This experiment clearly showed that chemical shift perturbations for unmodified EF-P are stronger than for rhamnosylated EF-P (Fig. 6B). Thus, EarP releases EF-P after rhamnosylation due to decreased affinity, while unmodified EF-P binds with higher affinity to enable efficient posttranslational modification.

Mutational analysis of the three invariant EarP residues D13, D17, and E273. We and others previously showed that EarP inverts the anomeric configuration on the sugar moiety from TDP- $\beta$-L-rhamnose to $\alpha$-rhamnosyl arginine $(26,27)$. Reportedly, inverting glycosyltransferases employ a direct-displacement $S_{N} 2$-like reaction (46). The molecular basis for inverted $\mathrm{N}$-linked glycosylation was elucidated for the oligosaccharyl transferase PglB (47). Here the catalytic site features three acidic side chains (29). As with PglB, three negatively charged residues-aspartates D13EarP and D17EarP and glutamate E273EarP_were identified as potential candidates to catalyze the glycosylation reaction (Fig. 3B). All three residues are invariant in all EarP orthologues (Fig. 4A; Data Set S3). Moreover, the D13EarP and D17EarP variants as well as the E273EarP variant are in the vicinity of the rhamnose moiety and might therefore be proximal to the putative active center and R32 of EF-P (Fig. 3B). The distances of these three residues to rhamnose atoms range from 2.5 to $4.5 \AA$ (the carboxyl group of D13 is the closest, with a distance of $2.5 \AA$ to the methyl group of the rhamnose, followed by the side chains of D17 and E273, with distances of 3.9 and $4.5 \AA$ to the hydroxyl group of C4 and $C 2$, respectively). Consequently, we constructed the corresponding alanine substitution variants D13A EarP, D17A EarP, and E273A EarP and investigated their enzymatic activities in vitro. In line with the idea that these residues might be involved in catalysis, EF-P rhamnosylation could not be detected even after $8 \mathrm{~h}$ of incubation, and accordingly these EarP variants are inactive (Fig. 7A).

To exclude misfolding being causative for the nonfunctional EarP $P_{P p u}$ protein variants, ${ }^{15} \mathrm{~N}$ HSQCs were measured for D13A EarP, D17A EarP, and E273A EarP. The spectra show no structural alterations from WTEarP (Fig. 7B, C, and D and see Fig. S7). Additionally, the variants D13AEarP and D17A EarP were titrated with TDP-Rha being indistinguishable from WTEarP perturbations. Interestingly, although D13 EarP and D17EarP resonances could not be assigned, other residues in close proximity (G16 ${ }^{\text {EarP }}$ and G19EarP) exhibited strong perturbations not only in WTEarP but also in the D13A EarP and D17A EarP variants upon TDP-Rha binding, despite not forming direct ligand contacts (Fig. 7E). Similarly, we could measure TDP-Rha binding for E273A/D/NEarP variants using STD NMR (Fig. S5C). This confirms that these mutations do not affect donor substrate binding.

To investigate interactions between EF-P $P_{P p u}$ and the D13AEarP, D17A EarP, and E273AEarP variants, we again performed a bacterial two-hybrid analysis and were able to show that all substitution variants are capable of acceptor binding, demonstrated by a blue colony on X-Gal (5-bromo-4-chloro-3-indolyl- $\beta$-D-galactopyranoside)-containing LB plates (Fig. 7F, S1C).

To further corroborate our findings on the in vitro-inactive D13AEarP, D17AEarP, and $E 273 A^{\text {EarP }}$ variants, they were subjected to an in vivo experiment in which we investigated their ability to activate EF-P $P_{P p u}$ (Fig. 5A). Additional substitutions-D13N/EEarP, D17N/EEarP, and E273Q/DEarP — were also included in the study. Expectedly, coproduction of the D13A ${ }^{\text {EarP }}, D 17 A^{\text {EarP }}$, and E273A ${ }^{\text {EarP }}$ variants with EF-P $P_{P p u}$ phenocopies $\Delta$ efp 
A

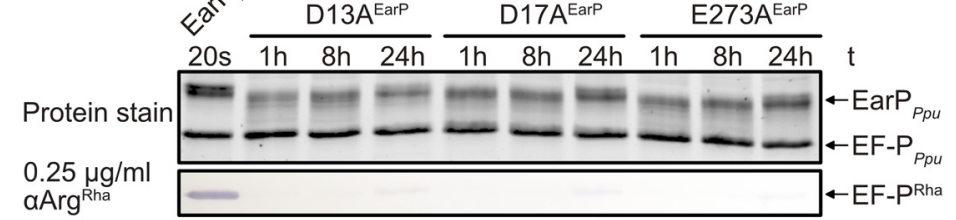

E
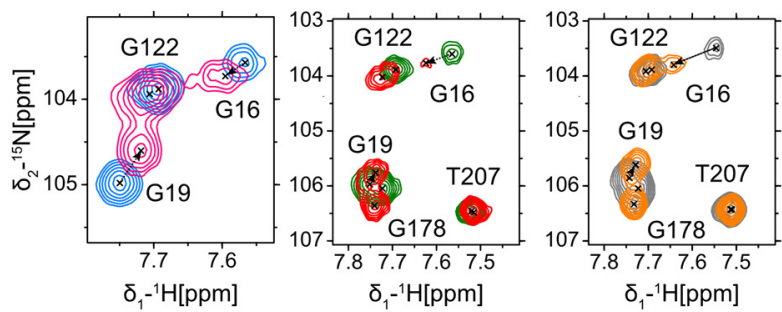

$\mathrm{F}$
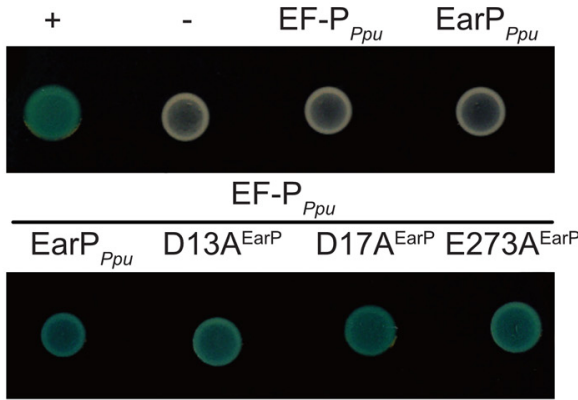

G

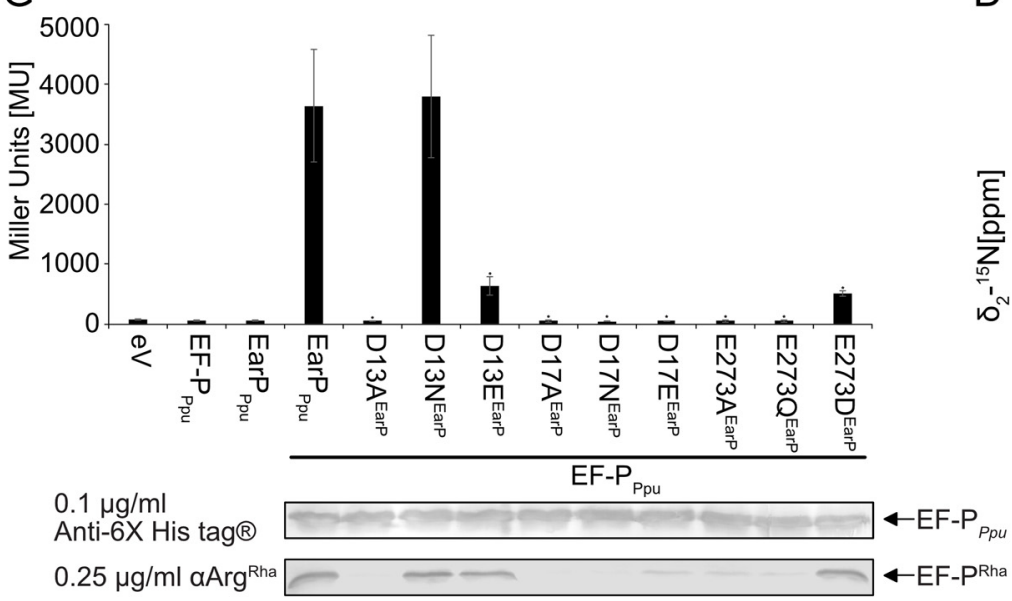

B

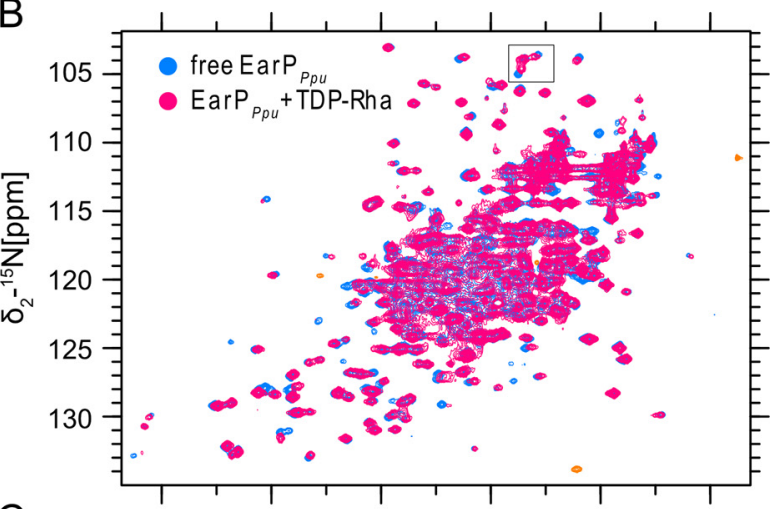

C
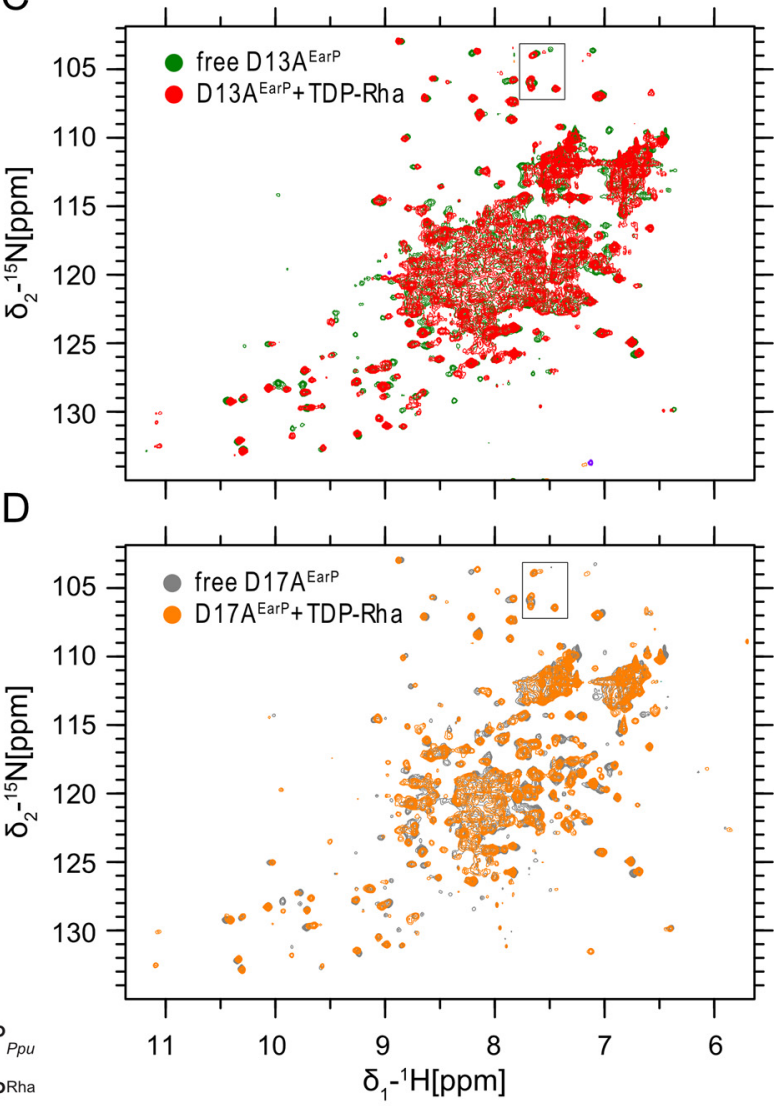

FIG 7 Mutational analysis of the three invariant EarP residues D13, D17, and E273. (A) In vitro rhamnosylation of EF-P $P_{p \text { pu }}$ by single-amino-acid exchange variants, specifically, D13A EarP, D17A EarP, and E273A EarP variants. EF-P $(2.5 \mu \mathrm{M})$ and TDP-Rha $(1 \mathrm{mM})$ were incubated together with the EarP $\mathrm{P}_{p u}$ variants $(0.5 \mu \mathrm{M})$ and sampled at different time points. Rhamnosylated EF-P $P_{P p u}$ (EF-PRha) was detected after Western blotting using $0.25 \mu \mathrm{g} / \mathrm{ml}$ anti-ArgRha. (B) Overlay of ${ }^{1} \mathrm{H}-{ }^{15} \mathrm{~N}$ HSQC spectra of wild-type EarP ${ }_{P p u}$ that was free and bound to TDP-Rha. (C) Overlay of ${ }^{1} \mathrm{H}-{ }^{-15} \mathrm{~N}$ HSQC spectra of the free and TDP-Rha-bound D13AEarP variant. (D) Overlay of ${ }^{1} \mathrm{H}-{ }^{15} \mathrm{~N}$ HSQC spectra of the free and TDP-Rha-bound D17AEarP variant. The color coding is indicated in the upper left corner of each spectrum. The titrations are described in detail in Materials and Methods. (E) Zoom into the overlaid spectra shown in panels B, C, and D. The position of the zoom is indicated by a black frame in the corresponding original overlay. Peak assignments are shown. The movement of G16 and G19 upon TDP-Rha titration is indicated by dashed arrows. (F) Bacterial two-hybrid analysis of protein-protein interactions between EarP ${ }_{\text {p pu }}$ the D13A EarP, D17A EarP, and E273A EarP variants, and the protein acceptor EF- $P_{P p u}$ in E. coli BTH101. The blue color of colonies results from cleavage of X-Gal by $\beta$-galactosidase and indicates protein-protein interaction between

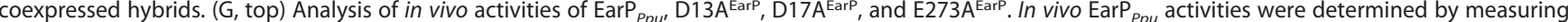

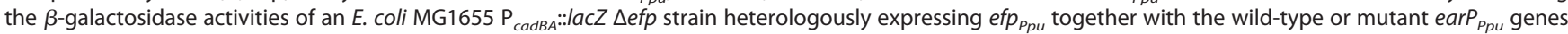
from $\mathrm{o} / \mathrm{n}$ cultures in $\mathrm{LB}$ (pH 5.8). Means of three independent measurements are shown. Standard deviations from three independent experiments were determined. (Bottom) Western blot analysis of o/n cultures of E. coli MG1655 $\mathrm{P}_{\text {cadBA }}:$ :lacZ $\Delta$ efp heterologously expressing efp $p_{P p u}$ together with the wild-type or earP $P_{P p u}$ mutants. Rhamnosylated EF-P $P_{P p u}$ (EF-PRha) was detected using $0.25 \mu \mathrm{g} / \mathrm{ml}$ anti-ArgRha.

with respect to $\mathrm{P}_{\text {CadBA }}$ activation and in vivo rhamnosylation (Fig. 7G; Fig. S1B). Similar results were obtained with the D17N/EEarP and E273QEarP variants, whereas the D13EEarP and E273DEarP variants were drastically impaired in function, although they retained some residual activity. Their impairment is indicated by a certain degree of 
$\mathrm{P}_{\text {CadBA }}$ activation as well as a band in the in vivo rhamnosylation blot (Fig. 7G; Fig. S1B). In contrast, a variant with a change of D13 to asparagine was indistinguishable from WTEarP, implying an importance of the chain length over charge.

Our thorough analysis of these EarP variants suggests that they are promising candidates to be involved in catalysis.

\section{DISCUSSION}

Activation of the proline-specific translation elongation factors EF-P and IF-5A is usually achieved by posttranslational elongation of the $\varepsilon$-amino group of a conserved lysine $(20-23,48,49)$. The resultant noncanonical amino acids $-\beta$-lysinyl-hydroxylysine, hypusine, and 5-amino-pentanolyl-lysine-appear to be chemically and structurally analogous. We recently showed that in a subset of bacteria, a so-far-unappreciated form of posttranslational modification plays an important role in the activation of EF-P. Here, instead of lysine, the guanidine group of a conserved arginine is modified with a rhamnose moiety by a glycosyltransferase termed EarP (17). This type of modification not only contrasts with the other known EF-P/IF-5A activation strategies but is also one of only two reported cases of enzyme-mediated arginine glycosylation. In canonical $\mathrm{N}$-linked glycosylation, the sugar is attached to the amide nitrogen of an asparagine in an $\mathrm{N}-\mathrm{X}-\mathrm{S} / \mathrm{T}$ consensus sequence ( $\mathrm{X}$ is any amino acid except for a proline) $(46,50)$. In contrast, the effector glycosyltransferase NleB of enteropathogenic $E$. coli $\mathrm{N}$-acetylglucosaminylates (GlcNAc) specifically the arginines at positions 117 and 235 in the death domain-containing proteins FADD and TRADD, respectively $(31,51)$. This in turn antagonizes the apoptosis of infected cells, thereby blocking a major antimicrobial host response. Notably, EarP shows neither sequential nor structural homologies to the GT-A-type glycosyltransferase NleB, and thus the arginine glycosylation of death domains and EF-P are examples of convergent evolution. Instead EarP seems to be structurally related to MurG. Moreover, and despite the lack of a significant overall sequence similarity, certain residues important for function remain the same. According to these facts, one might speculate that EarP is not simply analogous to MurG but a distinct homologue. Note that MurG is essential for cell wall biosynthesis in both Gram-negative and Gram-positive bacteria, and due to its degree of conservation, it is most likely more ancient then EarP. Although there is no real evidence for this, one might hypothesize about the possibility of a duplication of MurG in a betaproteobacterial progenitor, which is the presumed origin of EarP (17). Subsequently, the sequences of both proteins more and more diverged in consequence of distinct donor and acceptor substrates. This assumption is at least also in line with the theory that NleB (GT-A type) and EarP (GT-B type) are phylogenetically nonrelated enzymes. Accordingly, one can also assume that the molecular mechanisms of the glycosyl transfer reactions in both arginine glycosyltransferases differ. In 2016, Wong Fok Lung and coworkers mutated nleB and identified certain residues in NleB either interfering with FADD binding or preventing GlcNAcylation (52). They confirmed the importance of two invariant aspartate residues, D221 and D223, from among the nonfunctional NleB protein variants (31). A catalytic Asp-X-Asp motif is featured by various GT-A glycosyltransferases. Here, the two negatively charged aspartate side chains coordinate a divalent cation that facilitates departure of the nucleoside phosphate. Negatively charged amino acids also play important catalytic roles in inverting GT-B glycosyltransferases (46). In the case of the metal-independent fucosyltransferase FucT (53), for example, the side chain carboxyl groups of D13 and E95 may work as base catalysts (46). Also, the activation of the acceptor amide nitrogen by the lipid donor utilizing bacterial oligosaccharyltransferase PgIB depends on the two negatively charged amino acids D56 and E319. These residues abolish the conjugation of the nitrogen electrons and allow the positioning of a free electron pair for the nucleophilic attack onto the anomeric center of the donor substrate $(29,47)$. Analogously, the invariant negatively charged residues D13 EarP, D17EarP, and E273EarP in the EarP glycosyltransferase family might play a role in activating the R32 guanidino group of EF-P. Especially D17EarP and E273 EarP — both in close proximity to each other-may form a catalytic dyad (Fig. 3B). 
While activation of the acceptor substrate might be driven by the essential amino acids D13 EarP, D17EarP, and E273EarP, the nucleotide sugar donor TDP-Rha is bound in a highly conserved cavity of the protein $C$ domain. A cocrystal structure of the putative structural EarP analogue $M u r G_{E c o}$ with its cognate substrate reveals that aromatic amino acid side chains play important roles in UDP binding (PDB accession number $1 N L M)$ (54). Similar interactions were reported for the protein O-fucosyltransferase POFUT1 (PDB accession number 3ZY6), where F357 is involved in $\pi$-stacking with the respective nucleobase (55). Stacking interactions also play a role in EarP, in which the aromatic side chains of F252 EarP and F258 EarP bind the thymine and ribose moiety of TDP-Rha, respectively. In contrast, contacts with the ribose or the phosphate moieties frequently occur via interactions with side chain amines, hydroxyl groups, and backbone amides $(37,54,55)$. Accordingly, this is also the case for EarP.

In GT-B glycosyltransferases, positively charged amino acids are often involved in facilitating leaving group departure. This is achieved by neutralization of evolving negative charges on the phosphate moiety during the glycosyl transfer reaction, as described, e.g., for R261 of MurG $_{E c o}$ (PDB accession number 1F0K) (37). Notably, earP $P_{P p u}$ encodes an invariant R271 EarP in the equivalent position and a substitution to alanine (R271A EarP) strongly impairs protein function, all of which suggests that they have similar roles in product stabilization.

In GT-B glycosyltransferases, the two Rossmann folds can generally be divided into one donor and one acceptor substrate binding domain (40). As with other glycosyltransferases, the nucleotide sugar is bound by the protein C-domain of EarP. Accordingly, it is worth assuming important binding sites for EF-P in the protein N-domain. Conversely, EF-P presumably contacts EarP by amino acids that are in close proximity to the glycosylation site R32 ${ }^{\mathrm{EF}-\mathrm{P}}$. In agreement with this hypothesis, the EF-P $\beta$-lysine ligase EpmA, for example, recognizes EF-P via identity elements in a region located around the E. coli EF-P modification site $\mathrm{K} 34(21,22,56)$. Along the same line, the deoxyhypusine synthase (DHS) can efficiently modify a human elF-5A fragment comprising only the first 90 amino acids of the protein (57). Similarly, we could show that the KOW-like N-terminal domain of EF-P (Fig. 6B) is sufficient to be glycosylated by EarP (Fig. 6D), being congruent with the NMR titrations of EF-P with EarP (Fig. 6A to C). Upon titration with EarP, the chemical shift perturbations observed were (with a few exceptions) restricted to the first 65 residues.

Taking all of this together, we propose a three-step model for the rhamnosylation of EF-P by its cognate modifier EarP. In the ground state, both the nucleotide sugar binding site in the $\mathrm{C}$-domain and the putative acceptor binding site in the $\mathrm{N}$-domain are unoccupied.

In the donor-bound state, TDP-Rha is coordinated within a highly conserved cavity in the protein $\mathrm{C}$-domain, including an aromatic pocket that surrounds the thymine ring (Fig. 3). Previous studies showed that binding of the donor substrate induces structural alterations in both the $\mathrm{N}$ and C-domains of glycosyltransferases $(40,58,59)$. In MurG, these rearrangements include rotation of F244, which stacks over the nucleobase to cap the donor binding pocket (37). Notably, in the crystal structure of EarP, a phenylalanine, F252, is in the equivalent position, indicating that this capping interaction is conserved (Fig. 3A) (54).

In the catalytic state, the R32 guanidino group of EF-P might be activated by a mechanism analogous to the one that was reported for the oligosaccharyltransferase PglB (47). Hence, in the EF-P rhamnosylation reaction, R271EarP might stabilize the nucleotide product, thereby facilitating leaving group departure. Upon successful inverting glycosyl transfer from TDP-Rha to R32 $2^{\text {EF-P }}$, presumably by a single $\mathrm{S}_{\mathrm{N}} 2$ displacement reaction, the products are released from the active site of EarP, in turn reverting to the unbound ground state.

We point out that there is most likely no strict sequence of binding events, as NMR measurements demonstrate that EarP can interact with either substrate independently.

Altogether, our structural and biochemical investigation of EarP provides first insights into arginine glycosylation and improves our general understanding of 
$\mathrm{N}$-linked glycosyl transfer reactions. Additionally, our research might open up new avenues for the development of antimicrobial drugs in order to fight, e.g., P. aeruginosa infections.

\section{MATERIALS AND METHODS}

Bacterial strains and growth conditions. Strains and plasmids used in this study are listed in Data Set S1 in the supplemental material. $P$. putida and E. coli were routinely grown in lysogeny broth (LB) $(60$, 61 ) according to the Miller modification (62) at $30^{\circ} \mathrm{C}$ (for P. putida) and $37^{\circ} \mathrm{C}$ (for E. coli), unless indicated otherwise. When required, media were solidified by using $1.5 \%$ (wt/vol) agar. If necessary, media were supplemented with $50 \mu \mathrm{g} / \mathrm{ml}$ chloramphenicol, $100 \mu \mathrm{g} / \mathrm{ml}$ kanamycin sulfate, and/or $100 \mu \mathrm{g} / \mathrm{ml} \mathrm{ampi-}$ cillin sodium salt. For promoter induction from $\mathrm{P}_{B A D}$-containing plasmids (63), L-arabinose was added to a final concentration of $0.2 \%$ (wt/vol) in liquid medium. For promoter induction from plasmids comprising the lac operator sequences, isopropyl $\beta$-D-1-thiogalactopyranoside (IPTG) (Sigma-Aldrich) was added to a final concentration of $1 \mathrm{mM}$.

Molecular biology methods. Enzymes and kits were used according to the manufacturers' directions. Genomic DNA was obtained according to the protocol of Pospiech and Neumann (64), and plasmid DNA was isolated using a Hi Yield plasmid minikit (Süd-Laborbedarf $\mathrm{GmbH}$ ). DNA fragments were purified from agarose gels by employing a Hi Yield PCR cleanup and gel extraction kit (Süd-Laborbedarf). Restriction endonucleases were purchased from New England Biolabs (NEB). Sequence amplifications by PCR were performed utilizing the Q5 high-fidelity DNA polymerase (NEB) or the OneTaq DNA polymerase (NEB). Mutations were introduced into the earP gene by overlap extension PCR $(65,66)$. Oligonucleotides used in this study are listed in Data Set S1. All constructs were analyzed by Sanger sequencing (LMU Sequencing Service). Standard methods were performed according to the instructions of Sambrook and Russel (67).

$\boldsymbol{\beta}$-Galactosidase activity assay. Cells expressing lac $Z$ under the control of the cadBA promoter were grown in buffered LB ( $\mathrm{pH} 5.8$ ) overnight $(\mathrm{o} / \mathrm{n})$ and harvested by centrifugation. $\beta$-Galactosidase activities were determined as described in reference 68 in biological triplicates and are given in Miller units (MU) (69). The significance of the results was determined by applying a two-sided Student $t$ test and stating a result as significantly different if $P$ was $<0.05$.

Bacterial two-hybrid analysis. Protein-protein interactions were detected using the bacterial adenylate cyclase two-hybrid system kit (Euromedex) according to the product manuals. Chemically competent (70) E. coli BTH101 cells were cotransformed with pUT18C-efp $p_{p p u}$ and/or the respective pKT25 variants (pKT25-earP, pKT25-D13A, pKT25-D17A, pKT25-F191A, pKT25-Y193A, pKT25-F252A, pKT25Q255A, pKT25-F258A, pKT25-R271A，pKT25-D274A，pKT25-S275A, pKT25-R278A, pKT25-Y291A, pKT25E273A) and plated on LB screening medium containing $40 \mu \mathrm{g} / \mathrm{ml} 5$-bromo-4-chloro-3-indolyl- $\beta$-Dgalactopyranoside (X-Gal) and $0.5 \mathrm{mM}$ IPTG as well as $50 \mu \mathrm{g} / \mathrm{ml}$ kanamycin sulfate and $100 \mu \mathrm{g} / \mathrm{ml}$ ampicillin sodium salt. Transformants containing pUT18-zip and pKT25-zip were used as positive controls. Transformants carrying pUT18C and pKT25 vector backbones were used as negative controls. Bacteria expressing interacting protein hybrids exhibit a blue phenotype on screening plates due to functional complementation of the CyaA fragments (T18 and T25). After $48 \mathrm{~h}$ of incubation at $30^{\circ} \mathrm{C}$, plates containing around 100 colonies were evaluated. Representative colonies were transferred to liquid LB cultures containing kanamycin sulfate and ampicillin sodium salt and incubated $\mathrm{o} / \mathrm{n}$ at $30^{\circ} \mathrm{C}$. Subsequently, $2 \mu \mathrm{l}$ of the o/n culture were spotted on LB X-Gal-IPTG screening plates. Pictures were taken after $48 \mathrm{~h}$ of cultivation at $30^{\circ} \mathrm{C}$.

For quantification of interaction strength, which corresponds to the $\beta$-galactosidase activity, cells were inoculated in $1.5 \mathrm{ml} \mathrm{LB}$ medium containing $0.5 \mathrm{mM}$ IPTG as well as $50 \mu \mathrm{g} / \mathrm{ml}$ kanamycin sulfate and $100 \mu \mathrm{g} / \mathrm{ml}$ ampicillin sodium salt. After incubation in 2-ml reaction tubes under microaerobic conditions at $30^{\circ} \mathrm{C}$ for $42 \mathrm{~h}$, cells were harvested and $\beta$-galactosidase activities were determined as described above.

Protein purification. C-terminally $\mathrm{His}_{6}$-tagged EarP $_{P p u}$ variants ( $\mathrm{pBAD} 33$-earP $P_{P p u}$ ) were overproduced in E. coli LMG194 by addition of $0.2 \%$ arabinose to exponentially growing cells and subsequent cultivation at $18^{\circ} \mathrm{Co}$ on. N-terminally $\mathrm{His}_{6}$-tagged EarP (pACYC-DUET-earP $P_{P p u}$ ) and $\mathrm{His}_{6}-\mathrm{SUMO}_{\text {-tagged }}$ EF-P $P_{P p u}$ (pET-SUMO-efp $p_{P p u}$ ) were overproduced in E. coli BL21(DE3) by addition of $1 \mathrm{mM}$ IPTG to exponentially growing cells. Subsequently, cells were incubated at $18^{\circ} \mathrm{C}$ overnight. Rhamnosylated

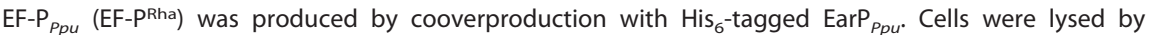
sonication, and $\mathrm{His}_{6}$-tagged proteins were purified using Ni-nitrilotriacetic acid (Ni-NTA; Qiagen) according to the manufacturer's instructions. The $\mathrm{His}_{6}-\mathrm{SUMO}$ tag was removed by incubation with $1 \mu / \mathrm{mg}$ $\mathrm{His}_{6}$-Ulp1 (71) overnight. Subsequently, tag-free EF-P ${ }_{P p u}$ was collected from the flowthrough after metal chelate affinity chromatography. For biochemical analyses, cells were cultivated in LB. For use in NMR spectroscopy, cells were grown in $\mathrm{M} 9$ minimal medium (62). If necessary, ${ }^{15} \mathrm{~N}$-labeled nitrogen $\left({ }^{15} \mathrm{NH}_{4} \mathrm{Cl}\right)$ and ${ }^{13} \mathrm{C}$-labeled glucose were used. For NMR backbone assignment of EarP ${ }_{\text {Ppu }}$ additionally $99.8 \%$-pure heavy water $\mathrm{D}_{2} \mathrm{O}$ (Sigma-Aldrich) was used instead of $\mathrm{H}_{2} \mathrm{O}$ in growth medium to allow partial deuteration of the protein in order to reduce cross-relaxation effects and increase the signal-to-noise ratio. Size exclusion chromatography of $\operatorname{EarP}_{P p u}$ and the D274AEarP variant was performed in $100 \mathrm{mM} \mathrm{NaP} \mathrm{i}_{\mathrm{i}}(\mathrm{pH}$ 7.6) $50 \mathrm{mM} \mathrm{NaCl}$ using a Superdex 200 Increase 10/300-Gl column with a flow rate of $0.3 \mathrm{ml} / \mathrm{min}$ on an Äkta purifier (GE Healthcare). Four milligrams of protein was loaded in a volume of $0.5 \mathrm{ml}(8 \mathrm{mg} / \mathrm{ml})$. Eluting protein was detected at $280 \mathrm{~nm}$. Fractions of $0.5 \mathrm{ml}$ were collected.

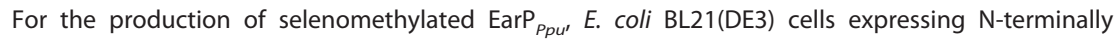

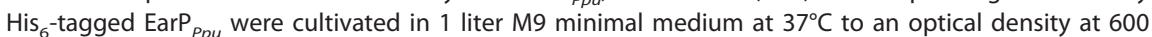



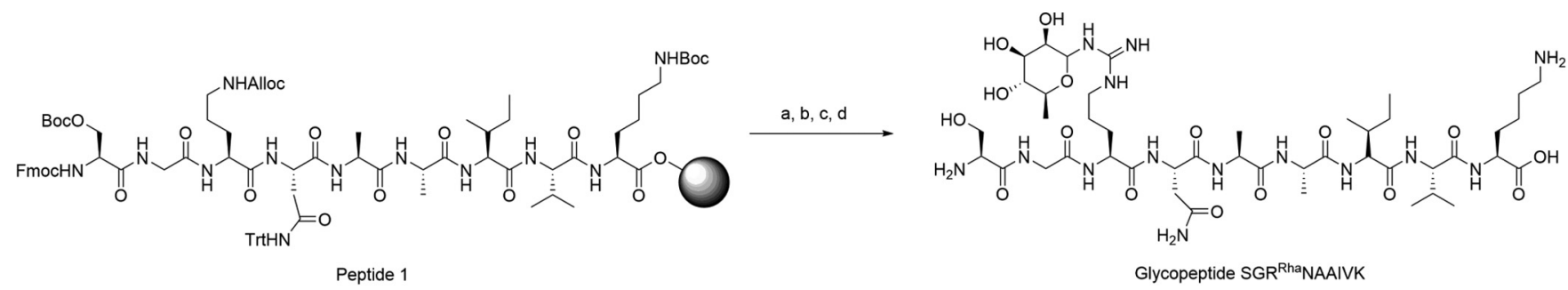

FIG 8 Synthesis of glycopeptide SGR RhaNAAIVK. a, $\mathrm{SiPhH}_{3}$ (phenylsilane), $\mathrm{Pd}\left(\mathrm{PPh}_{3}\right)_{4}, \mathrm{CH}_{2} \mathrm{Cl}_{2} ;$ b, 1-(tert-butoxycarbonyl)-3-(2,3,4-tri-O-acetyl-6-deoxy-L-mannopyranos1-yl)-2-ethyl-isothiourea (26) $\mathrm{AgNO}_{3}$ (silver nitrate), $\mathrm{NEt}_{3}$ (triethylamine), DMF; c, $\mathrm{N}_{2} \mathrm{H}_{4} \cdot \mathrm{H}_{2} \mathrm{O}\left(5 \%\right.$ solution in DMF); d, TFA-H $\mathrm{H}_{2} \mathrm{O}-\mathrm{phenol}-\mathrm{TIPS}(88 / 5 / 5 / 2)$.

$\mathrm{nm}\left(\mathrm{OD}_{600}\right)$ of 0.6 . One hundred micrograms of threonine, $100 \mu \mathrm{g}$ lysine, and $50 \mu \mathrm{g}$ isoleucine were added to feedback inhibit methionine biosynthesis (72). Additionally, $50 \mu \mathrm{g} \mathrm{L}-(+)$-selenomethionine was added 15 min prior to induction. Protein production was induced by addition of $1 \mathrm{mM}$ IPTG, and cells were incubated at $18^{\circ} \mathrm{C}$ overnight. Protein concentrations were determined as described by Bradford (73). For biochemical analyses, EarP $P_{P p u}$ and EF-P ${ }_{P p u}$ were dialyzed against $100 \mathrm{mM} \mathrm{NaP}{ }_{\mathrm{i}}, \mathrm{pH} 7.6,5 \mathrm{mM}$ dithiothreitol (DTT), whereas a buffer composed of $100 \mathrm{mM} \mathrm{NaP}_{\mathrm{i}}, \mathrm{pH} 7.6,50 \mathrm{mM} \mathrm{NaCl}$, and $5 \mathrm{mM}$ DTT was used when the proteins were subjected to NMR analysis.

Synthesis of a single rhamnosyl-arginine containing glycopeptide. Moisture- and air-sensitive reactions were conducted in flame-dried glassware under an argon atmosphere. Commercially available reagents and solvents were used without further purification. $\mathrm{CH}_{2} \mathrm{Cl}_{2}$ was distilled from calcium hydride, and tetrahydrofuran (THF) was distilled from sodium benzophenone immediately prior to use. Dimethylformamide (DMF) was stored under argon in a flask containing $4 \AA$ molecular sieves. Reactions were monitored by thin layer chromatography (TLC) with precoated Silica Gel $60 \mathrm{~F}_{254}$ aluminum plates (Merck, Darmstadt, Germany) using UV light and methoxyphenol reagent ( $100 \mathrm{ml} 0.2 \%$ ethanolic methoxyphenol solution and $100 \mathrm{ml} 2 \mathrm{M}$ ethanolic sulfuric acid) as the visualizing agent. Flash chromatography was performed using silica gel (35 to $70 \mu \mathrm{m}$ ) from Acros Organics. Peptide purification by reverse-phase high-performance liquid chromatography (RP-HPLC) was performed on a JASCO purification system with a UV-visible-light detector (model UV-2075Plus) using a Phenomenex Aeris Peptide 5- $\mu \mathrm{m}$ XB- $\mathrm{C}_{18}$ column ( 250 by $21.2 \mathrm{~mm}$ ). Analytical RP-HPLC was measured on a JASCO system with a Phenomenex Aeris Peptide $5-\mu \mathrm{m} \mathrm{XB-C_{18 }}$ column ( 250 by $4.6 \mathrm{~mm}$ ). In all cases, mixtures of water (eluent $\mathrm{A}$ ) and acetonitrile (eluent B) were used as eluents; if required, $0.1 \%$ formic acid (FA) or $0.1 \%$ trifluoroacetic acid (TFA) was added. High-resolution electrospray ionization (HR-ESI) mass spectra were recorded on a Thermo Finnegan LTQ FT mass spectrometer or on a Bruker maxis apparatus equipped with a Waters ACQUITY ultrahigh-performance liquid chromatograph (UPLC) using a Kinetex $C_{18}$ column $(2.6 \mu \mathrm{m}, 100 \AA)$ at $40^{\circ} \mathrm{C}$ (Fig. 8).

Glycopeptide SGR RhaNAAIVK was synthesized using a Liberty Blue automated microwave peptide synthesizer, followed by on-resin glycosylation and deprotection (Fig. 8). For construction of peptide 1, $0.1 \mathrm{mmol}$ of preloaded $\mathrm{H}$-Lys(Boc)-2-chlorotrityl resin (loading concentration, $0.78 \mathrm{mmol} / \mathrm{g}$ ) was applied. Cleavage of the Fmoc-protecting group was achieved with $20 \%$ piperidine in $\mathrm{DMF}\left(75^{\circ} \mathrm{C}, 35 \mathrm{~W}, 3 \mathrm{~min}\right)$. Fmoc-protected amino acids (5 eq) were activated for peptide coupling using 5 eq of ethyl (hydroxyimino)cyanoacetate (Oxyma Pure), 0.5 eq of $N, N$-diisopropylethylamine (DIPEA), and 5 eq of $N, N^{\prime}$ diisopropylcarbodiimide. All coupling reactions were conducted at $75^{\circ} \mathrm{C}$ and $28 \mathrm{~W}$ for $5 \mathrm{~min}$. Removal of the allyloxycarbonyl-protecting group and subsequent coupling of the sugar moiety, as well as deprotection of the acetyl groups, were performed according to established procedures (26). Final deprotec-

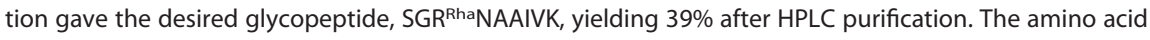
sequence of the glycopeptide corresponds to the primary structure of the S. oneidensis acceptor loop, which is highly similar to the consensus sequence of EarP-arginine-type EF-Ps (17).

High-resolution mass spectrometry (HRMS) $\left(E S I^{+}\right)$, calculated for $\mathrm{C}_{44} \mathrm{H}_{82} \mathrm{~N}_{14} \mathrm{O}_{16}[\mathrm{M}+2 \mathrm{H}]^{2+}, \mathrm{m} / \mathrm{z}=$ 531.3011; found, 531.3016.

$\operatorname{HPLC}(0.1 \%$ TFA, $0 \mathrm{~min}, 8 \% \mathrm{~B} \rightarrow 45 \mathrm{~min}, 50 \% \mathrm{~B}$; flow, $1 \mathrm{ml} / \mathrm{min}), t_{R}$ (retention time) $=9.61 \mathrm{~min}, \lambda=$ 204 nm (Fig. 9).

Antibody generation. Polyclonal antibodies were raised commercially by Eurogentec according to the Rabbit Speedy 28-day (AS superantigen) program. The mono-rhamnosyl-arginine-containing peptide was coupled to bovine serum albumin (BSA) according to an internal protocol (AS-PECO 05). Antibodies capable of binding to rhamnosyl-arginine were purified from rabbit sera by affinity chromatography (AS-PURI-MED) against the glycopeptide SGR RhaNAAIVK. To test the specificity of the purified polyclonal antibodies toward EF-PRha, $1.5 \mu \mathrm{g}$ of unmodified and $0.5 \mu \mathrm{g}$ of modified EF-P were transferred to a nitrocellulose membrane by Western blotting. While polyclonal antibodies that were raised against EF-P from $S$. oneidensis detect both unmodified and modified EF-P $P_{P p u}$ anti-Arg ${ }^{\text {Rha }}$ specifically detects the modified protein variant (Fig. S1A).

SDS-PAGE and Western blotting. Electrophoretic separation of proteins was carried out using SDS-PAGE as described by Lämmli (74). Separated proteins were visualized in gel using $0.5 \%$ (vol/vol) 2-2-2-trichloroethanol (75) and transferred onto a nitrocellulose membrane by vertical Western blotting. Antigens were detected using $0.1 \mu \mathrm{g} / \mathrm{ml}$ anti-His ${ }_{6}$ tag (Abcam, Inc.), $0.2 \mu \mathrm{g} / \mathrm{ml}$ anti-EF-P, or $0.25 \mu \mathrm{g} / \mathrm{ml}$ of anti-Arg Rha. Primary antibodies (rabbit) were targeted by $0.2 \mu \mathrm{g} / \mathrm{ml}$ alkaline phosphatase-conjugated anti-rabbit lgG (H\&L) (goat) antibody (Rockland). Target proteins were visualized by addition of substrate 


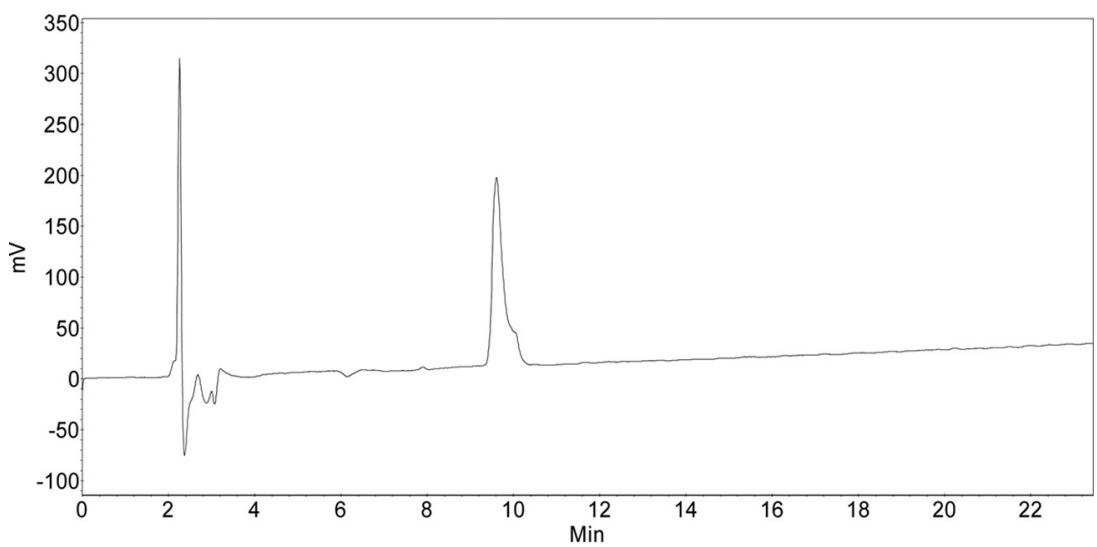

FIG 9 HPLC data.

solution (50 mM sodium carbonate buffer, $\mathrm{pH} 9.5,0.01 \%$ [wt/vol] nitroblue tetrazolium, $0.045 \%$ [wt/vol] 5-bromo-4-chloro-3-indolylphosphate).

Determination of kinetic parameters. Kinetic parameters were determined by varying TDP-Rha concentrations while keeping concentrations of $\operatorname{EarP}_{P p u}(0.1 \mu \mathrm{M})$ and unmodified EF- $P_{P p u}(2.5 \mu \mathrm{M})$ constant. A mixture of EarP $P_{P p u}$ and unmodified EF- $P_{P p u}$ was equilibrated to $30^{\circ} \mathrm{C}$ in $100 \mathrm{mM} \mathrm{NaP}$ i $(\mathrm{pH} \mathrm{7.6)}$. The reaction was started by the addition of TDP-Rha and was stopped after $20 \mathrm{~s}$ of incubation at $30^{\circ} \mathrm{C}$ by the addition of 1 vol of $2 \times$ Lämmli buffer (74) and incubation at $95^{\circ} \mathrm{C}$ for $5 \mathrm{~min}$. Samples were subjected to SDS-PAGE, and rhamnosylated EF-P $P_{p u}$ was detected as described above. Band intensities were quantified using ImageJ (76). Product formation (in nanomoles per milligram) was calculated relative to fully (in vivo) rhamnosylated EF-P $P_{p p u} \cdot K_{m}$ and $k_{\text {cat }}$ values were determined by fitting reaction rates (in nanomoles per milligram per second) to the Michaelis-Menten equation using SigmaPlot. Time course experiments conducted at a TDP-Rha concentration of $500 \mu \mathrm{M}$ show that the rhamnosylation reaction is not saturated after $20 \mathrm{~s}$ of incubation (Fig. S2A).

Fold recognition. Fold recognition models were generated using the online user interface of Phyre ${ }^{2}$ $(33,77)$, SWISS-MODEL $(78-81)$, and the I-TASSER server (34-36) as instructed on the websites. Model structures were selected from the array of results according to best confidence, $Q$ mean, and $z$ scores, respectively. All images of tertiary protein structures in this work were generated using the UCSF Chimera package developed by the Resource for Biocomputing, Visualization, and Informatics at the University of California, San Francisco (82). Protein structures were obtained as .pdb files from http://www.rcsb.org (83) or the respective modeling platforms mentioned above.

Determination of intracellular TDP-Rha concentrations. Cells were grown in 1 liter $L B$ to an $\mathrm{OD}_{600}$ of $0.5\left(5 \times 10^{8}\right.$ cells $\left./ \mathrm{ml}\right)$, harvested by centrifugation, and resuspended in $25 \mathrm{ml} 100 \mathrm{mM} \mathrm{NaP}$ ( $\left.\mathrm{pH} 7.6\right)$ $\left(2 \times 10^{10} \mathrm{cell} / \mathrm{s} / \mathrm{ml}\right)$. After disruption of cells with a Constant Systems Ltd. continuous-flow cabinet at 1.35 $\mathrm{kb}$, cell debris were removed by centrifugation and lysates were sterilized by filtration (Steriflip). A mixture of $\operatorname{EarP}_{P p u}(0.1 \mu \mathrm{M})$ and unmodified EF-P $P_{P p u}(2.5 \mu \mathrm{M})$ was equilibrated to $30^{\circ} \mathrm{C}$ in $10 \mu \mathrm{l} 100 \mathrm{mM}$ $\mathrm{NaP}_{\mathrm{i}}\left(\mathrm{pH}\right.$ 7.6). The reaction was started by addition of $10 \mu \mathrm{l}$ lysate from $\sim 2 \times 10^{7}$ or $\sim 2 \times 10^{8}$ cells and stopped after $20 \mathrm{~s}$ of incubation at $30^{\circ} \mathrm{C}$ by addition of $1 \mathrm{vol} 2 \times$ Lämmli buffer (74) and incubation at $95^{\circ} \mathrm{C}$ for $5 \mathrm{~min}$. In parallel, a TDP-Rha calibration series was generated by addition of TDP-Rha at final concentrations ranging from $5 \mu \mathrm{M}$ to $160 \mu \mathrm{M}$, including the linear range of the rhamnosylation reaction rate (Fig. 5D). Samples were subjected to SDS-PAGE, and rhamnosylated EF-P Ppu was detected as described above. Band intensities were quantified using ImageJ (76). TDP-Rha concentrations in samples containing lysate were calculated by dividing the respective relative band intensities by the slope of the corresponding calibration curve (5 $\mu \mathrm{M}$ to $80 \mu \mathrm{M}$ TDP-Rha). Intracellular TDP-Rha concentrations were calculated from the amount of substance (in moles) per cell, with an assumption of equal distribution of TDP-Rha across all cells as well as an average cell volume of $3.9 \mu \mathrm{m}^{3}$ for E. coli (84) and $2.1 \mu \mathrm{m}^{3}$ for P. putida and $P$. aeruginosa (85).

NMR spectroscopy and backbone assignment of EF-P and EarP. All NMR experiments were performed at $298 \mathrm{~K}$ on Bruker Avance III spectrometers with a magnetic field strength corresponding to a proton Larmor frequency of $600 \mathrm{MHz}$ (equipped with a Bruker TXI cryogenic probe head), $700 \mathrm{MHz}$ (equipped with a Bruker room temperature probe head), or $800 \mathrm{MHz}$ (equipped with a Bruker TXI cryogenic probe head). All data sets were processed using NMRPipe (91).

Before NMR measurements of ${ }^{15} \mathrm{~N}$ - and ${ }^{13} \mathrm{C}$-labeled EF-P $(700 \mu \mathrm{M})$ in $100 \mathrm{mM} \mathrm{NaP}{ }_{\mathrm{i}}, 50 \mathrm{mM} \mathrm{NaCl}$, and $5 \mathrm{mM} \mathrm{DTT}(\mathrm{pH} 7.6), 0.02 \% \mathrm{NaN}_{3}$ was added to the sample. Sequential resonance assignment was obtained from two-dimensional (2D) $1 \mathrm{H}-15 \mathrm{~N}$ HSQC and three-dimensional (3D) HNCA, CBCACONH, and HNCACB backbone experiments, using a constant time during ${ }^{13} \mathrm{C}$ evolution (86). The assignment process was assisted by CARA (http://cara.nmr.ch) and CcpNmr Analysis (63), and 98\% of the backbone resonances could be assigned. Missing assignments for residues other than prolines are S123, R133, N140, V164, D175, and G185. Secondary chemical shift analysis was performed based on the difference between measured ${ }^{13} \mathrm{C}_{\alpha}$ and ${ }^{13} \mathrm{C}_{\beta}$ chemical shifts and random coil chemical shifts of the same nuclei to assign a secondary structure to the EF-P sequence (Fig. S3E) and confirm the validity of the model shown in Fig. $6(87,88)$. 
Due to the size of EarP (43 kDa), backbone resonance assignment was possible only for ${ }^{2} \mathrm{H}-,{ }^{15} \mathrm{~N}-$, and ${ }^{13} \mathrm{C}$-labeled samples to reduce the number of protons and thus cross-relaxation effects, which also enables efficient acquisition of backbone assignment experiments in TROSY mode (89). TROSY-HNCA, -HNCACB, and -CBCACONH experiments (90), processed by NMRPipe (91) and analyzed using CARA (http://cara.nmr.ch), enabled backbone resonance assignment of $62 \%$ of all assignable residues (excluding prolines).

The NMR titrations were always performed by adding an unlabeled interaction partner to the ${ }^{15} \mathrm{~N}$-labeled protein sample and monitoring the progress of the titration by recording ${ }^{1} \mathrm{H}-{ }^{15} \mathrm{~N}$ HSQC. First, ${ }^{15} \mathrm{~N}$-labeled $150 \mu \mathrm{M}$ unmodified EF-P was titrated with unlabeled EarP to a 1:2 EF-P/EarP molar ratio with intermediate steps at 1:0, 1:0.5, 1:1, and 1:1.5 EF-P/EarP molar ratios. ${ }^{15} \mathrm{~N}$-labeled $41 \mu \mathrm{M}$ rhamnosylated EF-P was titrated with unlabeled EarP to a 1:2 EF-P/EarP molar ratio without any intermediate steps. ${ }^{15} \mathrm{~N}$-labeled $540 \mu \mathrm{M}$ wild-type EarP was titrated with unlabeled TDP-Rha to a 1:5 EarP/TDP-Rha molar ratio with intermediate steps at 1:0, 1:0.2, 1:1, and 1:3 molar ratios. ${ }^{15} \mathrm{~N}$-labeled $186 \mu \mathrm{M}$ D13A variant or $209 \mu \mathrm{M}$ D17A EarP variant was titrated by the addition of TDP-Rha to an approximately 1:10 molar ratio with no intermediate steps. To analyze the EF-P/EarP and wild-type EarP/TDP-Rha ratio titration, the chemical-shift perturbations (CSPs) were calculated according to the formula CSPs $=\sqrt{\Delta \sigma_{H}^{2}+\left(\Delta \sigma_{N} \times 0.15\right)^{2}}$, where 0.15 is the weighting factor to account for nitrogen resonances generally spanning a broad frequency range.

To check proper folding of EarP variants, ${ }^{1} \mathrm{H}-{ }^{15} \mathrm{~N}$ HSQC spectra of ${ }^{15} \mathrm{~N}$-labeled EarP variants with the following single-amino-acid substitutions at the indicated concentrations were recorded: $209 \mu \mathrm{M} \mathrm{D13A}$, $209 \mu \mathrm{M}$ D17A, $162 \mu \mathrm{M}$ F191A, $197 \mu \mathrm{M}$ Y193A, $139 \mu \mathrm{M}$ D274A, $186 \mu \mathrm{M}$ R271A, and $162 \mu \mathrm{M}$ Y291A.

STD NMR experiments were performed with $10 \mu \mathrm{M}$ WTEarP or mutants and either $70 \mu \mathrm{M}$ (1:7 ratio of protein to ligand to mimic SAXS conditions) or $1 \mathrm{mM}$ TDP-Rha in $100 \mathrm{mM}$ potassium phosphate buffer, $\mathrm{pH} 7.5,150 \mathrm{mM} \mathrm{NaCl}, 1 \mathrm{mM} \mathrm{DTT}$, and $10 \% \mathrm{D}_{2} \mathrm{O}$. The experiments were performed on a Bruker Avance III 700-MHz spectrometer equipped with a triple resonance (TXI) room temperature probe head at $277 \mathrm{~K}$. Protein was saturated with 49-ms Gaussian pulses at the resonance frequency of methyl resonances at $0.592 \mathrm{ppm}$. The experimental results were collected after a total saturation time of $20 \mathrm{~s}$, with 1,596 scans performed for the WTEarP sample with a 100-fold excess of ligand, and after a total saturation time of $5 \mathrm{~s}$, with 4,096 scans performed for the WTEarp sample with a 7-fold excess of ligand. For EarP mutants, the experimental results were collected after a total saturation time of $4 \mathrm{~s}$ and with 128 scans.

Small-angle X-ray scattering. Thirty microliters of EarP, EarP plus TDP-rhamnose, and buffer (with and without TDP-rhamnose) were measured at $20^{\circ} \mathrm{C}$ at BioSAXS beamline BM29 at the European Synchrotron Radiation Facility using a 2D Pilatus detector. For each measurement, 10 frames with a 1-s exposure time per frame were recorded for each EarP and buffer sample, using an X-ray wavelength $(\lambda)$ of $0.9919 \AA$. Measurements were performed in flow mode, where samples are pushed through a capillary at a constant flow rate to minimize radiation damage. The protein concentrations measured were 1.0, 2.0, 4.0 , and $8.0 \mathrm{mg} / \mathrm{ml}$. TDP-Rha was used in a 7:1 excess (ligand to protein). The buffer measurements were subtracted from each protein sample, and the low $Q$ range of $1.0 \mathrm{mg} / \mathrm{ml}$ was merged with the high $Q$ range of the $8.0-\mathrm{mg} / \mathrm{ml}$ sample, using PRIMUS (92). The merging was done due to the rising scattering density at low $\mathrm{Q}$ ranges for the more highly concentrated samples, indicative of aggregation. CRYSOL (93) was used to fit the back-calculated scattering densities from the crystal structure to the experimental data.

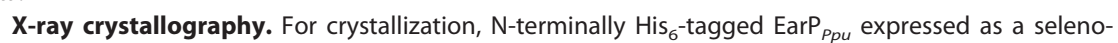
methionine derivative was used. The protein was dialyzed to $50 \mathrm{mM}$ Tris, $100 \mathrm{mM} \mathrm{NaCl}, 1 \mathrm{mM} \mathrm{DT}$, $\mathrm{pH}$ 7.6, and concentrated to $183 \mu \mathrm{M}$. TDP-Rha was added to a final concentration of $10 \mathrm{mM}$. The

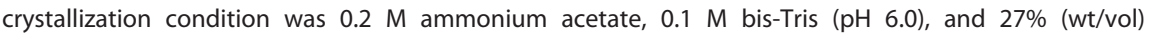
polyethylene glycol 3350. A full data set was collected at the ID29 beamline, ESRF, Grenoble, France, at a wavelength of $0.97 \AA$ (the absorption peak for selenium) and with a $15.05 \%$ beam transmission with a $0.15^{\circ}$ oscillation range, 0.037 -s exposure time, and 2,400 frames. The space group was determined to be 14. The data set was phased using single-wavelength anomalous diffraction (SAD) by the Crank2 (94) automatic pipeline in CCP4 (95), using Afro provided by N. S. Pannu (unpublished) for substructure factor amplitude (FA) estimation, Crunch2 (96) for substructure detection, and Solomon (97) for density modification. The anomalous signal extended to a $3.4-\AA \AA$ resolution (in a data set with a $3-\AA$ resolution). We could successfully find 3 Se-Met signals with an occupancy of 1 located in the C-terminal domain and 2 Se-Met signals with an occupancy of $\sim 0.5$ located in the N-terminal domain. The initial structure was built in Phenix Autobuild (98), completed with several rounds of manual model building in Coot (99), and used as the model for molecular replacement (MR) of a native data set extending to $2.3 \AA$. Despite our rigorous efforts in manual model building, which included extreme density modification, use of homology models to model the N-terminal domain, Rosetta modeling, and refinement strategies with different refinement software (Phenix [98], refmac [100], and CNS [101, 102] [and CNS-DEN-assisted refinement]), the structure displays an R-free of $35 \%$ at $2.3 \AA$, with large parts of the electron density in the $\mathrm{N}$-domain not interpretable. No crystallographic pathology (twinning, anisotropy) could be identified in any of the multiple data sets that we obtained, and trying to interpret crystallographic symmetry as noncrystallographic symmetry by deliberately choosing space groups with lower symmetry (C2, P1) did not improve the density. This indicates intrinsic crystal disorder caused by the $\mathrm{N}$-terminal domain adopting several conformations in different unit cells.

Accession number(s). Atomic coordinates and structure factors for the reported crystal structures have been deposited with the Protein Data Bank under accession number 5NV8. 
SUPPLEMENTAL MATERIAL

Supplemental material for this article may be found at https://doi.org/10.1128/mBio

.01412-17.

FIG S1, TIF file, 1.8 MB.

FIG S2, TIF file, 3.6 MB.

FIG S3, TIF file, 10.7 MB.

FIG S4, TIF file, 7.9 MB.

FIG S5, TIF file, 3.2 MB.

FIG S6, TIF file, 6.9 MB.

FIG S7, TIF file, 3.1 MB.

DATA SET S1, XLSX file, 0.02 MB.

DATA SET S2, XLSX file, 0.01 MB.

DATA SET S3, XLSX file, $0.1 \mathrm{MB}$.

\section{ACKNOWLEDGMENTS}

We thank Ingrid Weitl for excellent technical assistance. We thank Wolfram Volkwein for fruitful discussions. The SAXS and X-ray diffraction experiments were performed on beamlines BM29 and ID29/ID23-1, respectively, at the European Synchrotron Radiation Facility (ESRF), Grenoble, France. We are grateful to local contacts at the ESRF for providing assistance in using beamlines BM29, ID29, and ID23-1. We are also grateful to Christoph Müller, Irmgard Sinning, and Klemens Wild for fruitful discussions regarding the crystal structure of EarP. Lastly, we thank Bernard Henrissat and the glycogenomics group at AFMB in Marseille, France, for building EarP into the CAZy database as the new family GT104.

J.L., K.J., and A.H.R. gratefully acknowledge financial support from the DFG Research Training Group GRK2062 (Molecular Principles of Synthetic Biology). Moreover, J.L. is grateful for DFG grant LA 3658/1-1. J.H. acknowledges support from the European Molecular Biology Laboratory (EMBL). P.K.A.J. acknowledges EMBL and the EU Marie Curie Actions Cofund for an EIPOD fellowship. K.J. and A.H.R. additionally thank the Center for integrated Protein Science Munich (Cluster of Excellence grant Exc114/2). The work of J.R., P.M., and A.K.J. was supported by U.S. National Institutes of Health grant GM 105977.

A.H.R., S.W., and D.G. performed the organic synthesis and NMR analysis of small molecules and wrote the corresponding section of Materials and Methods. R.K. performed the confirmation of antibody specificity raised against the rhamnosyl-argininecomprising peptide. Additionally, R.K. constructed the EarP $P_{P p u^{-}}$and EF-P $P_{P p u^{-}}$-encoding plasmids and purified all proteins used for biochemical analyses, NMR studies, and X-ray crystallography. R.K. also performed the biochemical in vivo/in vitro characterization of EarP $_{P p u}$ and determined concentrations of TDP- $\beta$-L-rhamnose in E. coli, P. putida, and $P$. aeruginosa. TDP- $\beta$-L-rhamnose was synthesized by J.R., P.M., and A.K.J. J.H., J.M., and P.K.A.J. performed and analyzed all protein NMR experiments. The crystallization screen was set up by J.M. J.H., and J.M., and P.K.A.J. solved the crystal structure of EarP Ppu. J.L., J.H., and K.J. designed the study. The manuscript was written by R.K., J.M., P.K.A.J., K.J., J.H., and J.L.

\section{REFERENCES}

1. Varenne S, Buc J, Lloubes R, Lazdunski C. 1984. Translation is a nonuniform process. Effect of tRNA availability on the rate of elongation of nascent polypeptide chains. J Mol Biol 180:549-576. https://doi.org/10 .1016/0022-2836(84)90027-5.

2. Pavlov MY, Watts RE, Tan Z, Cornish VW, Ehrenberg M, Forster AC. 2009. Slow peptide bond formation by proline and other $\mathrm{N}$-alkylamino acids in translation. Proc Natl Acad Sci U S A 106:50-54. https://doi.org/10 .1073/pnas.0809211106.

3. Tanner DR, Cariello DA, Woolstenhulme CJ, Broadbent MA, Buskirk AR. 2009. Genetic identification of nascent peptides that induce ribosome stalling. J Biol Chem 284:34809-34818. https://doi.org/10.1074/jbc .M109.039040.
4. Woolstenhulme CJ, Parajuli S, Healey DW, Valverde DP, Petersen EN, Starosta AL, Guydosh NR, Johnson WE, Wilson DN, Buskirk AR. 2013. Nascent peptides that block protein synthesis in bacteria. Proc Natl Acad Sci U S A 110:E878-E887. https://doi.org/10.1073/pnas.1219536110.

5. Gutierrez E, Shin BS, Woolstenhulme CJ, Kim JR, Saini P, Buskirk AR, Dever TE. 2013. elF5A promotes translation of polyproline motifs. Mol Cell 51:35-45. https://doi.org/10.1016/j.molcel.2013.04.021.

6. Pelechano V, Alepuz P. 2017. elF5A facilitates translation termination globally and promotes the elongation of many non polyproline-specific tripeptide sequences. Nucleic Acids Res https://doi.org/10.1093/nar/ gkx479.

7. Schuller AP, Wu CC, Dever TE, Buskirk AR, Green R. 2017. elF5A func- 
tions globally in translation elongation and termination. Mol Cell 66: 194-205.e5. https://doi.org/10.1016/j.molcel.2017.03.003.

8. Doerfel LK, Wohlgemuth I, Kothe C, Peske F, Urlaub H, Rodnina MV 2013. EF-P is essential for rapid synthesis of proteins containing consecutive proline residues. Science 339:85-88. https://doi.org/10.1126/ science.1229017.

9. Hersch SJ, Wang M, Zou SB, Moon KM, Foster LJ, lbba M, Navarre WW. 2013. Divergent protein motifs direct elongation factor P-mediated translational regulation in Salmonella enterica and Escherichia coli. mBio 4:e00180-13. https://doi.org/10.1128/mBio.00180-13.

10. Peil L, Starosta AL, Lassak J, Atkinson GC, Virumäe K, Spitzer M, Tenson T, Jung K, Remme J, Wilson DN. 2013. Distinct XPPX sequence motifs induce ribosome stalling, which is rescued by the translation elongation factor EF-P. Proc Natl Acad Sci U S A 110:15265-15270. https://doi .org/10.1073/pnas.1310642110.

11. Ude S, Lassak J, Starosta AL, Kraxenberger T, Wilson DN, Jung K. 2013. Translation elongation factor EF-P alleviates ribosome stalling at polyproline stretches. Science 339:82-85. https://doi.org/10.1126/science .1228985 .

12. Elgamal S, Katz A, Hersch SJ, Newsom D, White $P$, Navarre WW, Ibba M. 2014. EF-P dependent pauses integrate proximal and distal signals during translation. PLoS Genet 10:e1004553. https://doi.org/10.1371/ journal.pgen.1004553.

13. Starosta AL, Lassak J, Peil L, Atkinson GC, Virumäe K, Tenson T, Remme J, Jung K, Wilson DN. 2014. Translational stalling at polyproline stretches is modulated by the sequence context upstream of the stall site. Nucleic Acids Res 42:10711-10719. https://doi.org/10.1093/nar/ gku768.

14. Woolstenhulme CJ, Guydosh NR, Green R, Buskirk AR. 2015. Highprecision analysis of translational pausing by ribosome profiling in bacteria lacking EFP. Cell Rep 11:13-21. https://doi.org/10.1016/j.celrep .2015.03.014.

15. Hanawa-Suetsugu K, Sekine S, Sakai H, Hori-Takemoto C, Terada T, Unzai S, Tame JR, Kuramitsu S, Shirouzu M, Yokoyama S. 2004. Crystal structure of elongation factor $\mathrm{P}$ from Thermus thermophilus HB8. Proc Natl Acad Sci U S A 101:9595-9600. https://doi.org/10.1073/pnas .0308667101

16. Blaha G, Stanley RE, Steitz TA. 2009. Formation of the first peptide bond: the structure of EF-P bound to the $70 \mathrm{~S}$ ribosome. Science 325:966-970. https://doi.org/10.1126/science.1175800.

17. Lassak J, Keilhauer EC, Fürst M, Wuichet K, Gödeke J, Starosta AL, Chen JM, Søgaard-Andersen L, Rohr J, Wilson DN, Häussler S, Mann M, Jung K. 2015. Arginine-rhamnosylation as new strategy to activate translation elongation factor P. Nat Chem Biol 11:266-270. https://doi.org/10 .1038/nchembio.1751.

18. Doerfel LK, Wohlgemuth I, Kubyshkin V, Starosta AL, Wilson DN, Budisa N, Rodnina MV. 2015. Entropic contribution of elongation factor $P$ to proline positioning at the catalytic center of the ribosome. J Am Chem Soc 137:12997-13006. https://doi.org/10.1021/jacs.5b07427.

19. Lassak J, Wilson DN, Jung K. 2016. Stall no more at polyproline stretches with the translation elongation factors EF-P and IF-5A. Mol Microbiol 99:219-235. https://doi.org/10.1111/mmi.13233.

20. Bailly M, de Crécy-Lagard V. 2010. Predicting the pathway involved in post-translational modification of elongation factor $P$ in a subset of bacterial species. Biol Direct 5:3. https://doi.org/10.1186/1745-6150-5-3.

21. Navarre WW, Zou SB, Roy $H$, Xie JL, Savchenko A, Singer A, Edvokimova E, Prost LR, Kumar R, Ibba M, Fang FC. 2010. PoxA, YjeK, and elongation factor $\mathrm{P}$ coordinately modulate virulence and drug resistance in Salmonella enterica. Mol Cell 39:209-221. https://doi.org/10.1016/j.molcel .2010.06.021.

22. Yanagisawa T, Sumida T, Ishii R, Takemoto C, Yokoyama S. 2010. A paralog of lysyl-tRNA synthetase aminoacylates a conserved lysine residue in translation elongation factor P. Nat Struct Mol Biol 17: 1136-1143. https://doi.org/10.1038/nsmb.1889.

23. Peil L, Starosta AL, Virumäe K, Atkinson GC, Tenson T, Remme J, Wilson DN. 2012. Lys34 of translation elongation factor EF-P is hydroxylated by YfcM. Nat Chem Biol 8:695-697. https://doi.org/10.1038/nchembio .1001.

24. Rajkovic A, Erickson S, Witzky A, Branson OE, Seo J, Gafken PR, Frietas MA, Whitelegge JP, Faull KF, Navarre W, Darwin AJ, Ibba M. 2015. Cyclic rhamnosylated elongation factor $P$ establishes antibiotic resistance in Pseudomonas aeruginosa. mBio 6:e00823. https://doi.org/10.1128/mBio .00823-15.

25. Yanagisawa T, Takahashi H, Suzuki T, Masuda A, Dohmae N, Yokoyama
S. 2016. Neisseria meningitidis translation elongation factor $\mathrm{P}$ and its active-site arginine residue are essential for cell viability. PLoS One 11:e0147907. https://doi.org/10.1371/journal.pone.0147907.

26. Li X, Krafczyk R, Macošek J, Li YL, Zou Y, Simon B, Pan X, Wu QY, Yan F, Li S, Hennig J, Jung K, Lassak J, Hu HG. 2016. Resolving the $\alpha$-glycosidic linkage of arginine-rhamnosylated translation elongation factor $\mathrm{P}$ triggers generation of the first Arg Rha specific antibody. Chem Sci 7:6995-7001. https://doi.org/10.1039/c6sc02889f.

27. Wang S, Corcilius L, Sharp PP, Rajkovic A, Ibba M, Parker BL, Payne RJ. 2017. Synthesis of rhamnosylated arginine glycopeptides and determination of the glycosidic linkage in bacterial elongation factor $P$. Chem Sci 8:2296-2302. https://doi.org/10.1039/C6SC03847F.

28. Coutinho PM, Deleury E, Davies GJ, Henrissat B. 2003. An evolving hierarchical family classification for glycosyltransferases. J Mol Biol 328:307-317. https://doi.org/10.1016/S0022-2836(03)00307-3.

29. Breton C, Fournel-Gigleux S, Palcic MM. 2012. Recent structures, evolution and mechanisms of glycosyltransferases. Curr Opin Struct Biol 22:540-549. https://doi.org/10.1016/j.sbi.2012.06.007.

30. Singh DG, Lomako J, Lomako WM, Whelan WJ, Meyer HE, Serwe M, Metzger JW. 1995. $\beta$-Glucosylarginine: a new glucose-protein bond in a self-glucosylating protein from sweet corn. FEBS Lett 376:61-64. https://doi.org/10.1016/0014-5793(95)01247-6.

31. Pearson JS, Giogha $C$, Ong SY, Kennedy CL, Kelly M, Robinson KS, Lung TW, Mansell A, Riedmaier P, Oates CV, Zaid A, Mühlen S, Crepin VF Marches O, Ang CS, Williamson NA, O'Reilly LA, Bankovacki A, Nachbur U, Infusini G, Webb Al, Silke J, Strasser A, Frankel G, Hartland EL. 2013. A type III effector antagonizes death receptor signalling during bacterial gut infection. Nature 501:247-251. https://doi.org/10.1038/ nature12524.

32. Guex N, Peitsch MC. 1997. SWISS-MODEL and the Swiss-Pdb Viewer: an environment for comparative protein modeling. Electrophoresis 18: 2714-2723. https://doi.org/10.1002/elps.1150181505.

33. Kelley LA, Sternberg MJ. 2009. Protein structure prediction on the Web: a case study using the Phyre server. Nat Protoc 4:363-371. https://doi .org/10.1038/nprot.2009.2.

34. Zhang Y. 2008. I-TASSER server for protein 3D structure prediction. BMC Bioinformatics 9:40. https://doi.org/10.1186/1471-2105-9-40.

35. Roy A, Kucukural A, Zhang Y. 2010. I-TASSER: a unified platform for automated protein structure and function prediction. Nat Protoc 5:725-738. https://doi.org/10.1038/nprot.2010.5.

36. Yang J, Yan R, Roy A, Xu D, Poisson J, Zhang Y. 2015. The I-TASSER suite: protein structure and function prediction. Nat Methods 12:7-8. https:// doi.org/10.1038/nmeth.3213.

37. Ha S, Walker D, Shi Y, Walker S. 2000. The 1.9 A crystal structure of Escherichia coli MurG, a membrane-associated glycosyltransferase involved in peptidoglycan biosynthesis. Protein Sci 9:1045-1052. https:// doi.org/10.1110/ps.9.6.1045.

38. Martinez-Fleites C, Macauley MS, He Y, Shen DL, Vocadlo DJ, Davies GJ. 2008. Structure of an O-GlcNAc transferase homolog provides insight into intracellular glycosylation. Nat Struct Mol Biol 15:764-765. https:// doi.org/10.1038/nsmb.1443.

39. Lombard V, Golaconda Ramulu H, Drula E, Coutinho PM, Henrissat B. 2014. The carbohydrate-active enzymes database (CAZy) in 2013. Nucleic Acids Res 42:D490-D495. https://doi.org/10.1093/nar/gkt1178.

40. Liang DM, Liu JH, Wu H, Wang BB, Zhu HJ, Qiao JJ. 2015. Glycosyltransferases: mechanisms and applications in natural product development. Chem Soc Rev 44:8350-8374. https://doi.org/10.1039/ c5cs00600g.

41. Viegas A, Manso J, Nobrega FL, Cabrita EJ. 2011. Saturation-transfer difference (STD) NMR: a simple and fast method for ligand screening and characterization of protein binding. J Chem Educ 88:990-994. https://doi.org/10.1021/ed101169t.

42. Sievers F, Higgins DG. 2014. Clustal Omega, accurate alignment of very large numbers of sequences. Methods Mol Biol 1079:105-116. https:// doi.org/10.1007/978-1-62703-646-7_6.

43. Boels IC, Beerthuyzen MM, Kosters MH, Van Kaauwen MP, Kleerebezem M, De Vos WM. 2004. Identification and functional characterization of the Lactococcus lactis $r f b$ operon, required for dTDPrhamnose biosynthesis. J Bacteriol 186:1239-1248. https://doi.org/ 10.1128/JB.186.5.1239-1248.2004.

44. Karimova G, Pidoux J, Ullmann A, Ladant D. 1998. A bacterial twohybrid system based on a reconstituted signal transduction pathway. Proc Natl Acad Sci U S A 95:5752-5756. https://doi.org/10.1073/pnas .95 .10 .5752 . 
45. Choi S, Choe J. 2011. Crystal structure of elongation factor $P$ from Pseudomonas aeruginosa at $1.75 \mathrm{~A}$ resolution. Proteins 79:1688-1693. https://doi.org/10.1002/prot.22992.

46. Lairson LL, Henrissat B, Davies GJ, Withers SG. 2008. Glycosyltransferases: structures, functions, and mechanisms. Annu Rev Biochem 77:521-555. https://doi.org/10.1146/annurev.biochem.76.061005.092322.

47. Lizak C, Gerber S, Numao S, Aebi M, Locher KP. 2011. X-ray structure of a bacterial oligosaccharyltransferase. Nature 474:350-355. https://doi .org/10.1038/nature10151.

48. Park MH, Cooper HL, Folk JE. 1982. The biosynthesis of protein-bound hypusine ( $\mathrm{N}^{\varepsilon_{-}}$(4-amino-2-hydroxybutyl)lysine). Lysine as the amino acid precursor and the intermediate role of deoxyhypusine $\left(\mathrm{N}^{\varepsilon_{-}}(4-\right.$ aminobutyl)lysine). J Biol Chem 257:7217-7222.

49. Rajkovic A, Hummels KR, Witzky A, Erickson S, Gafken PR, Whitelegge JP, Faull KF, Kearns DB, Ibba M. 2016. Translation control of swarming proficiency in Bacillus subtilis by 5-amino-pentanolylated elongation factor P. J Biol Chem 291:10976-10985. https://doi.org/10.1074/jbc .M115.712091.

50. Spiro RG. 2002. Protein glycosylation: nature, distribution, enzymatic formation, and disease implications of glycopeptide bonds. Glycobiology 12:43R-56R. https://doi.org/10.1093/glycob/12.4.43R.

51. Li S, Zhang L, Yao Q, Li L, Dong N, Rong J, Gao W, Ding X, Sun L, Chen X, Chen S, Shao F. 2013. Pathogen blocks host death receptor signalling by arginine GIcNAcylation of death domains. Nature 501:242-246. https://doi.org/10.1038/nature12436.

52. Wong Fok Lung T, Giogha C, Creuzburg K, Ong SY, Pollock GL, Zhang Y, Fung KY, Pearson JS, Hartland EL. 2016. Mutagenesis and functional analysis of the bacterial arginine glycosyltransferase effector NleB1 from enteropathogenic Escherichia coli. Infect Immun 84:1346-1360. https://doi.org/10.1128/IAI.01523-15.

53. Sun HY, Lin SW, Ko TP, Pan JF, Liu CL, Lin CN, Wang AH, Lin CH. 2007. Structure and mechanism of Helicobacter pylori fucosyltransferase. A basis for lipopolysaccharide variation and inhibitor design. J Biol Chem 282:9973-9982. https://doi.org/10.1074/jbc.M610285200.

54. Hu Y, Chen L, Ha S, Gross B, Falcone B, Walker D, Mokhtarzadeh M, Walker S. 2003. Crystal structure of the MurG:UDP-GICNAC complex reveals common structural principles of a superfamily of glycosyltransferases. Proc Natl Acad Sci U S A 100:845-849. https://doi.org/10.1073/ pnas.0235749100.

55. Lira-Navarrete E, Valero-González J, Villanueva R, Martínez-Júlvez M, Tejero T, Merino P, Panjikar S, Hurtado-Guerrero R. 2011. Structural insights into the mechanism of protein O-fucosylation. PLoS One 6:e25365. https://doi.org/10.1371/journal.pone.0025365.

56. Katz A, Solden L, Zou SB, Navarre WW, Ibba M. 2014. Molecular evolution of protein-RNA mimicry as a mechanism for translational control. Nucleic Acids Res 42:3261-3271. https://doi.org/10.1093/nar/gkt1296.

57. Joe YA, Park MH. 1994. Structural features of the elF-5A precursor required for posttranslational synthesis of deoxyhypusine. J Biol Chem 269:25916-25921.

58. Qasba PK, Ramakrishnan B, Boeggeman E. 2005. Substrate-induced conformational changes in glycosyltransferases. Trends Biochem Sci 30:53-62. https://doi.org/10.1016/j.tibs.2004.11.005.

59. Ni L, Sun M, Yu H, Chokhawala H, Chen X, Fisher AJ. 2006. Cytidine 5'-monophosphate (CMP)-induced structural changes in a multifunctional sialyltransferase from Pasteurella multocida. Biochemistry 45: 2139-2148. https://doi.org/10.1021/bi0524013.

60. Bertani G. 1951. Studies on lysogenesis. I. The mode of phage liberation by lysogenic Escherichia coli. J Bacteriol 62:293-300.

61. Bertani G. 2004. Lysogeny at mid-twentieth century: P1, P2, and other experimental systems. J Bacteriol 186:595-600. https://doi.org/10 .1128/JB.186.3.595-600.2004.

62. Miller JH. 1972. Experiments in molecular genetics. Cold Spring Harbor Laboratory Press, Cold Spring Harbor, NY.

63. Guzman LM, Belin D, Carson MJ, Beckwith J. 1995. Tight regulation, modulation, and high-level expression by vectors containing the arabinose $\mathrm{P}_{B A D}$ promoter. J Bacteriol 177:4121-4130. https://doi.org/10.1128/jb 177.14.4121-4130.1995.

64. Pospiech A, Neumann B. 1995. A versatile quick-prep of genomic DNA from gram-positive bacteria. Trends Genet 11:217-218. https://doi.org/ 10.1016/S0168-9525(00)89052-6.

65. Ho SN, Hunt HD, Horton RM, Pullen JK, Pease LR. 1989. Site-directed mutagenesis by overlap extension using the polymerase chain reaction. Gene 77:51-59. https://doi.org/10.1016/0378-1119(89)90358-2.

66. Lassak J, Henche AL, Binnenkade L, Thormann KM. 2010. ArcS, the cognate sensor kinase in an atypical Arc system of Shewanella oneidensis MR-1. Appl Environ Microbiol 76:3263-3274. https://doi.org/10 .1128/AEM.00512-10.

67. Sambrook J, Russell DW. 2001. Molecular cloning. A laboratory manual 3rd ed. Cold Spring Harbor Laboratory Press, Cold Spring Harbor, NY.

68. Tetsch L, Koller C, Haneburger I, Jung K. 2008. The membrane-integrated transcriptional activator CadC of Escherichia coli senses lysine indirectly via the interaction with the lysine permease LysP. Mol Microbiol 67:570-583. https://doi.org/10.1111/j.1365-2958.2007.06070.x.

69. Miller JH. 1992. A short course in bacterial genetics: a laboratory manual and handbook for Escherichia coli and related bacteria. Cold Spring Harbor Laboratory, Cold Spring Harbor, NY.

70. Inoue H, Nojima H, Okayama H. 1990. High efficiency transformation of Escherichia coli with plasmids. Gene 96:23-28. https://doi.org/10.1016/ 0378-1119(90)90336-P.

71. Starosta AL, Lassak J, Peil L, Atkinson GC, Woolstenhulme CJ, Virumäe K, Buskirk A, Tenson T, Remme J, Jung K, Wilson DN. 2014. A conserved proline triplet in Val-tRNA synthetase and the origin of elongation factor P. Cell Rep 9:476-483. https://doi.org/10.1016/j.celrep.2014.09 .008 .

72. Galili G. 1995. Regulation of lysine and threonine synthesis. Plant Cell 7:899-906. https://doi.org/10.1105/tpc.7.7.899.

73. Bradford MM. 1976. A rapid and sensitive method for the quantitation of microgram quantities of protein utilizing the principle of protein-dye binding. Anal Biochem 72:248-254. https://doi.org/10.1016/0003 $-2697(76) 90527-3$.

74. Laemmli UK. 1970. Cleavage of structural proteins during the assembly of the head of bacteriophage T4. Nature 227:680-685. https://doi.org/ 10.1038/227680a0.

75. Ladner CL, Yang J, Turner RJ, Edwards RA. 2004. Visible fluorescent detection of proteins in polyacrylamide gels without staining. Anal Biochem 326:13-20. https://doi.org/10.1016/j.ab.2003.10.047.

76. Schneider CA, Rasband WS, Eliceiri KW. 2012. NIH Image to ImageJ: 25 years of image analysis. Nat Methods 9:671-675. https://doi.org/10 .1038/nmeth.2089.

77. Kelley LA, Mezulis S, Yates CM, Wass MN, Sternberg MJE. 2015. The Phyre2 web portal for protein modeling, prediction and analysis. Nat Protoc 10:845-858. https://doi.org/10.1038/nprot.2015.053.

78. Arnold K, Bordoli L, Kopp J, Schwede T. 2006. The SWISS-MODEL workspace: a web-based environment for protein structure homology modelling. Bioinformatics 22:195-201. https://doi.org/10.1093/ bioinformatics/bti770.

79. Kiefer F, Arnold K, Künzli M, Bordoli L, Schwede T. 2009. The SWISSMODEL Repository and associated resources. Nucleic Acids Res 37: D387-D392. https://doi.org/10.1093/nar/gkn750.

80. Guex N, Peitsch MC, Schwede T. 2009. Automated comparative protein structure modeling with SWISS-MODEL and Swiss-Pdb Viewer: a historical perspective. Electrophoresis 30(Suppl 1):S162-S173. https://doi .org/10.1002/elps.200900140.

81. Biasini M, Bienert S, Waterhouse A, Arnold K, Studer G, Schmidt T, Kiefer F, Gallo Cassarino T, Bertoni M, Bordoli L, Schwede T. 2014. SWISSMODEL: modelling protein tertiary and quaternary structure using evolutionary information. Nucleic Acids Res 42:W252-W258. https://doi .org/10.1093/nar/gku340.

82. Pettersen EF, Goddard TD, Huang CC, Couch GS, Greenblatt DM, Meng EC, Ferrin TE. 2004. UCSF Chimera-a visualization system for exploratory research and analysis. J Comput Chem 25:1605-1612. https://doi .org/10.1002/jcc.20084.

83. Berman HM, Westbrook J, Feng Z, Gilliland G, Bhat TN, Weissig H, Shindyalov IN, Bourne PE. 2000. The Protein Data Bank. Nucleic Acids Res 28:235-242. https://doi.org/10.1093/nar/28.1.235.

84. Volkmer B, Heinemann M. 2011. Condition-dependent cell volume and concentration of Escherichia coli to facilitate data conversion for systems biology modeling. PLoS One 6:e23126. https://doi.org/10.1371/ journal.pone.0023126.

85. Cohen D, Mechold U, Nevenzal H, Yarmiyhu Y, Randall TE, Bay DC, Rich JD, Parsek MR, Kaever V, Harrison JJ, Banin E. 2015. Oligoribonuclease is a central feature of cyclic diguanylate signaling in Pseudomonas aeruginosa. Proc Natl Acad Sci U S A 112:11359-11364. https://doi.org/ 10.1073/pnas.1421450112.

86. Sattler M, Schleucher J, Griesinger C. 1999. Heteronuclear multidimensional NMR experiments for the structure determination of proteins in solution employing pulsed field gradients. Prog Nucl Magn Reson Spectrosc 34:93-158. https://doi.org/10.1016/S0079-6565(98)00025-9. 
87. Schwarzinger S, Kroon GJ, Foss TR, Chung J, Wright PE, Dyson HJ. 2001. Sequence-dependent correction of random coil NMR chemical shifts. J Am Chem Soc 123:2970-2978. https://doi.org/10.1021/ja003760i.

88. Wishart DS, Bigam CG, Holm A, Hodges RS, Sykes BD. 1995. 13 C and $15 \mathrm{~N}$ random coil NMR chemical shifts of the common amino acids. I. Investigations of nearest-neighbor effects. J Biomol NMR 5:67-81.

89. Pervushin K, Riek R, Wider G, Wüthrich K. 1997. Attenuated T2 relaxation by mutual cancellation of dipole-dipole coupling and chemical shift anisotropy indicates an avenue to NMR structures of very large biological macromolecules in solution. Proc Natl Acad Sci U S A 94: 12366-12371. https://doi.org/10.1073/pnas.94.23.12366.

90. Salzmann M, Pervushin K, Wider G, Senn H, Wüthrich K. 1998. TROSY in triple-resonance experiments: new perspectives for sequential NMR assignment of large proteins. Proc Natl Acad Sci U S A 95:13585-13590. https://doi.org/10.1073/pnas.95.23.13585.

91. Delaglio F, Grzesiek S, Vuister GW, Zhu G, Pfeifer J, Bax A. 1995. NMRPipe: a multidimensional spectral processing system based on UniX pipes. J Biomol NMR 6:277-293. https://doi.org/10.1007/BF00197809.

92. Konarev PV, Volkov VV, Sokolova AV, Koch MHJ, Svergun DI. 2003. PRIMUS-a Windows-PC based system for small-angle scattering data analysis. J Appl Crystallogr 36:1277-1282. https://doi.org/10.1107/ S0021889803012779.

93. Svergun DI, Barberato C, Koch MHJ. 1995. CRYSOL-a program to evaluate X-ray solution scattering of biological macromolecules from atomic coordinates. J Appl Crystallogr 28:768-773. https://doi.org/10 .1107/S0021889895007047.

94. Skubák P, Pannu NS. 2013. Automatic protein structure solution from weak X-ray data. Nat Commun 4:2777. https://doi.org/10.1038/ ncomms3777.

95. Winn MD, Ballard CC, Cowtan KD, Dodson EJ, Emsley P, Evans PR, Keegan RM, Krissinel EB, Leslie AG, McCoy A, McNicholas SJ, Murshudov GN, Pannu NS, Potterton EA, Powell HR, Read RJ, Vagin A, Wilson KS. 2011. Overview of the CCP4 suite and current developments. Acta Crystallogr D Biol Crystallogr 67:235-242. https://doi.org/10.1107/ S0907444910045749.

96. de Graaff RA, Hilge M, van der Plas JL, Abrahams JP. 2001. Matrix methods for solving protein substructures of chlorine and sulfur from anomalous data. Acta Crystallogr D Biol Crystallogr 57:1857-1862. https://doi.org/10.1107/S0907444901016535.

97. Abrahams JP, Leslie AG. 1996. Methods used in the structure determi- nation of bovine mitochondrial F1 ATPase. Acta Crystallogr D Biol Crystallogr 52:30-42. https://doi.org/10.1107/S0907444995008754.

98. Adams PD, Afonine PV, Bunkóczi G, Chen VB, Davis IW, Echols N, Headd JJ, Hung LW, Kapral GJ, Grosse-Kunstleve RW, McCoy AJ, Moriarty NW, Oeffner R, Read RJ, Richardson DC, Richardson JS, Terwilliger TC, Zwart PH. 2010. PHENIX: a comprehensive Python-based system for macromolecular structure solution. Acta Crystallogr D Biol Crystallogr 66: 213-221. https://doi.org/10.1107/S0907444909052925.

99. Emsley P, Cowtan K. 2004. Coot: model-building tools for molecular graphics. Acta Crystallogr D Biol Crystallogr 60:2126-2132. https://doi .org/10.1107/S0907444904019158.

100. Skubák P, Murshudov GN, Pannu NS. 2004. Direct incorporation of experimental phase information in model refinement. Acta Crystallogr D Biol Crystallogr 60:2196-2201. https://doi.org/10.1107/S090 7444904019079.

101. Brunger AT. 2007. Version 1.2 of the crystallography and NMR system. Nat Protoc 2:2728-2733. https://doi.org/10.1038/nprot.2007.406.

102. Brünger AT, Adams PD, Clore GM, DeLano WL, Gros P, Grosse-Kunstleve RW, Jiang JS, Kuszewski J, Nilges M, Pannu NS, Read RJ, Rice LM, Simonson T, Warren GL. 1998. Crystallography and NMR system: a new software suite for macromolecular structure determination. Acta Crystallogr D Biol Crystallogr 54:905-921. https://doi.org/10.1107/ S0907444998003254.

103. Shen Y, Delaglio F, Cornilescu G, Bax A. 2009. TALOS+: a hybrid method for predicting protein backbone torsion angles from NMR chemical shifts. J Biomol NMR 44:213-223. https://doi.org/10.1007/ s10858-009-9333-z.

104. Sievers F, Wilm A, Dineen D, Gibson TJ, Karplus K, Li W, Lopez R, McWilliam H, Remmert M, Söding J, Thompson JD, Higgins DG. 2011. Fast, scalable generation of high-quality protein multiple sequence alignments using Clustal Omega. Mol Syst Biol 7:539. https://doi.org/ 10.1038/msb.2011.75

105. Cao B, Porollo A, Adamczak R, Jarrell M, Meller J. 2006. Enhanced recognition of protein transmembrane domains with prediction-based structural profiles. Bioinformatics 22:303-309. https://doi.org/10.1093/ bioinformatics/bti784.

106. Vranken WF, Boucher W, Stevens TJ, Fogh RH, Pajon A, Llinas M, Ulrich EL, Markley JL, lonides J, Laue ED. 2005. The CCPN data model for NMR spectroscopy: development of a software pipeline. Proteins 59: 687-696. https://doi.org/10.1002/prot.20449. 